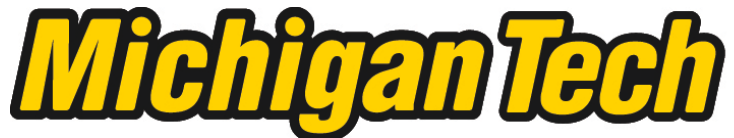 \\ Michigan Technological University Create the Future Digital Commons @ Michigan Tech
}

\section{Assessments and Computational Simulations in Support of a Time-Varying Mass Flow Rate Measurement Technique for Pulsatile Gas Flow}

Andrew Rice

Michigan Technological University

Follow this and additional works at: https://digitalcommons.mtu.edu/etds

Part of the Mechanical Engineering Commons

Copyright 2012 Andrew Rice

Recommended Citation

Rice, Andrew, "Assessments and Computational Simulations in Support of a Time-Varying Mass Flow Rate Measurement Technique for Pulsatile Gas Flow", Master's Thesis, Michigan Technological University, 2012.

https://doi.org/10.37099/mtu.dc.etds/461

Follow this and additional works at: https://digitalcommons.mtu.edu/etds

Part of the Mechanical Engineering Commons 


\title{
ASSESSMENTS AND COMPUTATIONAL SIMULATIONS IN SUPPORT OF A TIME-VARYING MASS FLOW RATE MEASUREMENT TECHNIQUE FOR PULSATILE GAS FLOW
}

\author{
By \\ Andrew F. Rice
}

\begin{abstract}
A THESIS
Submitted in partial fulfillment of the requirements for the degree of

MASTER OF SCIENCE

In Mechanical Engineering
\end{abstract}

MICHIGAN TECHNOLOGICAL UNIVERSITY

2012

(C) 2012 Andrew F. Rice 
This thesis has been approved in partial fulfillment of the requirements for the Degree of MASTER OF SCIENCE in Mechanical Engineering.

Department of Mechanical Engineering-Engineering Mechanics

Thesis Advisor:

Committee Member:

Committee Member:

Department Chair:
Amitabh Narain

Charles Margraves

Sunil Mehendale

William W. Predebon 


\section{Dedication Page}

\section{"To my family and friends"}

I dedicate my thesis work to my family and close friends who have supported me throughout this process. I will always appreciate all they have done.

I would also like to give a special thanks to my closest friends Gabrielle, Riva, and Delmar for being there for me throughout this entire endeavor. You have been my best supporters. 


\section{Table of Contents}

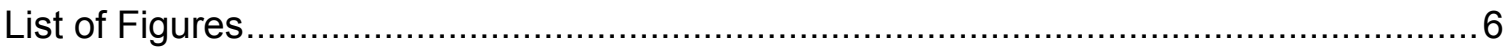

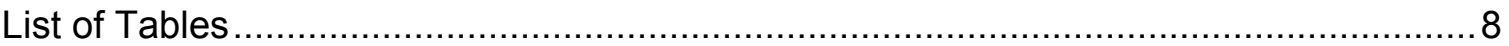

Preface

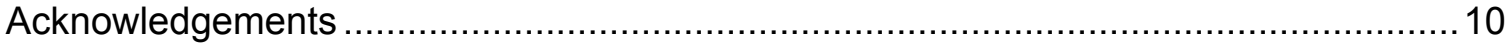

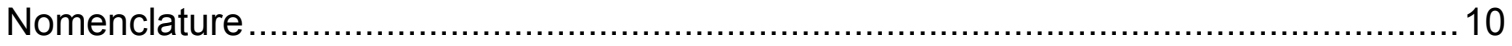

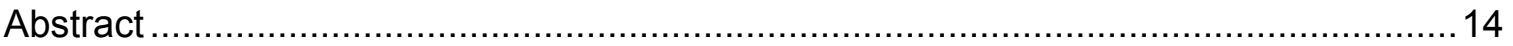

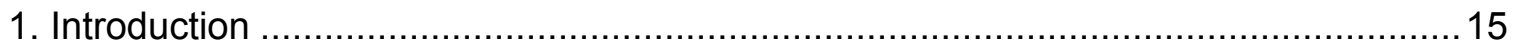

1.1 Inadequacy of Existing Approaches in Measuring the Pulsatile Mass Flow

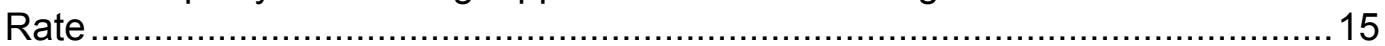

2. Experimental Procedures and Equipment...........................................................

2.1 Experimental System and Procedures.....................................................17

2.2 Instrumentation and Data Acquisition ..................................................... 18

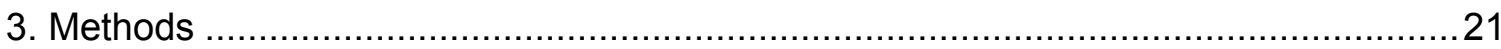

3.1 Mesh Construction and Verification............................................................2

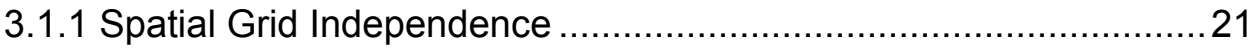

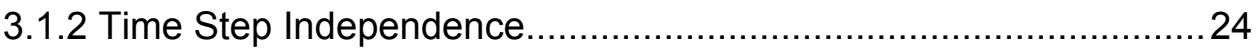

3.1.3 Turbulence Model and Solver Settings .........................................25

3.2 Empirical Corrections for the Mean Mass Flow Rate …….........................26

3.3 Incompressible and Isothermal Model Approach ………...........................27

3.3.1 Turbulence Model Independence Testing for Empirically Corrected Time-Varying Mass Flow Rates..........................................................29

3.4 Transient Compressibility Effects (Common between this thesis and

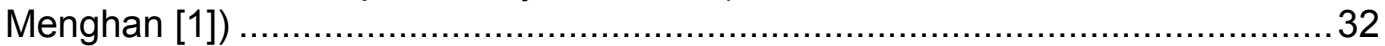

3.4.1 Cross-section Specific Mass Flow Rates Obtained from Transient Compressibility Corrections on the Incompressible Model Mass Flow Rate 
3.4.2 Compressible Flow Simulations as an Indirect Modeling Verification Approach

3.4.3 Alternative Indirect Modeling Verification Approach

3.4.4 An Indirect Modeling Verification Approach for the New Inlet Geometry.

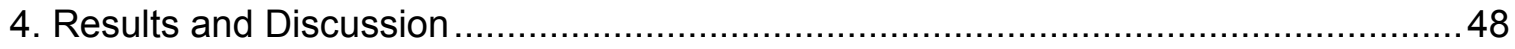

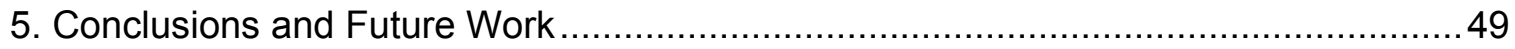

5.1 Uses in Future Experimental Research Work and Industry.......................49

5.2 Future Corrections and Verifications .................................................. 49

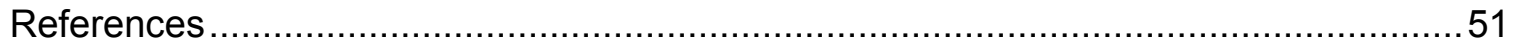

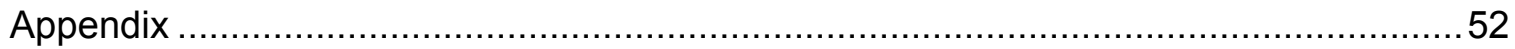

A-1 Initial Results from New Indirect Verification Approach as Proposed in Section 3.5

A-1.1 Mesh Construction and Grid Independence Testing for the New Inlet

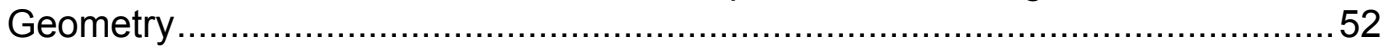

A-1.2 Preliminary Results for the Time Vary Mass Flow Rate of the New Inlet...53

A-2 A Recommended Experimental Approach for Direct Validation of the Orifice Meter

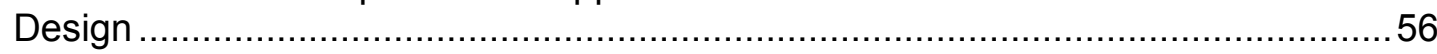




\section{List of Figures}

Figure 1: Full flow loop schematic with OM1 and OM2 shown................................17

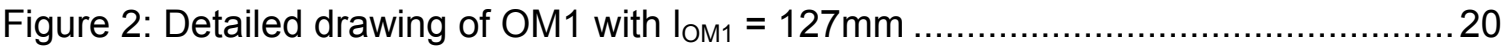

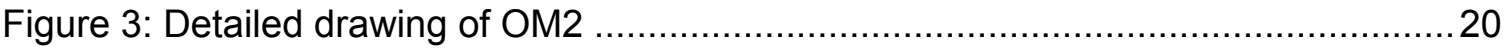

Figure 4: Steady state mass flow rates for varying mesh sizes ............................... 22

Figure 5: Velocity profiles at $x=0.12 \mathrm{~m}$ and $t=0.8235$ seconds for three mesh sizes $\ldots 22$

Figure 6: Pressure difference signal in the time domain for Case 3 of Table $4 \ldots \ldots \ldots \ldots . . .23$

Figure 7: Axial velocity at $x=0.12 \mathrm{~m}$ and $t=0.8235$ seconds for different time steps $\ldots . .25$

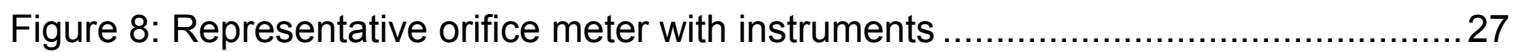

Figure 9: The representative solution that is associated with the pressure difference in Fig. 6.

Figure 10: Plot of the mass flow rate for two different turbulence models (Mod-1 and Mod-2) of run 3 in Table 4

Figure 11: For the representative values of $\dot{\mathrm{m}}_{\mathrm{CFD}-\mathrm{I} \mid \mathrm{OM} 1}(\mathrm{t})$ and $\dot{\mathrm{m}}_{\mathrm{CFD}-\mathrm{I} \mid \mathrm{OM} 2}(\mathrm{t})$ in Fig. 9 , the Figure above shows the respective empirically corrected values $\dot{\mathrm{m}}_{\mathrm{Inc} \mid \mathrm{OM} 1}(\mathrm{t})=\alpha$. $\dot{\mathrm{m}}_{\mathrm{CFD}-\mathrm{I} \mid \mathrm{OM} 1}(\mathrm{t})$ and $\dot{\mathrm{m}}_{\mathrm{Inc} \mid \mathrm{OM} 2}(\mathrm{t})=\alpha \cdot \dot{\mathrm{m}}_{\mathrm{CFD}-\mathrm{I} \mid \mathrm{OM} 2}(\mathrm{t})$ for turbulence model Mod 1 . In addition, the figure also shows $\dot{\mathrm{m}}_{\mathrm{Inc} \mid \mathrm{OM} 1}(\mathrm{t})$ for turbulence model Mod 2

Figure 12: The time-varying values of pressure fluctuation at cross-sections located by point $\mathrm{L}\left(\mathrm{p}_{\mathrm{L}}^{\prime}(\mathrm{t}) \equiv \mathrm{p}_{\mathrm{L}}(\mathrm{t})-\overline{\mathrm{p}}_{\mathrm{L}}\right)$ and $\mathrm{M}\left(\mathrm{p}_{\mathrm{M}}^{\prime}(\mathrm{t}) \equiv \mathrm{p}_{\mathrm{L}}^{\prime}(\mathrm{t})-\Delta \mathrm{p}_{\mathrm{OM} 1}(\mathrm{t})\right)$. These data are for run 4 of Tables 4-5

Figure 13: The FFT of $p_{L}^{\prime}$ and $p_{M}^{\prime}$ in Fig.12

Figure 14: The incompressible mass flow rate values of $\dot{\mathrm{m}}_{\mathrm{Inc|OM} 1}(\mathrm{t})$ for run 6 and its compressibility corrected values $\dot{\mathrm{m}}_{\mathrm{L}}(\mathrm{t})$ and $\dot{\mathrm{m}}_{\mathrm{M}}(\mathrm{t})$, respectively associated with points $\mathrm{L}$ and $\mathrm{M}$ in Fig. 2, are shown

Figure 15: For run 3 in Tables 4-5, the comparison between $\dot{\mathrm{m}}_{\text {stored }}(\mathrm{t})$ values obtained from the compressible flow CFD model and their values obtained from the proposed compressibility correction theory (Eq. (17)) for the incompressible CFD model (which has $\dot{\mathrm{m}}_{\text {stored }}(\mathrm{t})=0$ )

Figure 16: This plot shows, for run 3 in Tables 4-5, the comparison between mass flow rate $\dot{\mathrm{m}}_{\mathrm{M} \text {-Comp }}(\mathrm{t})$ obtained from the compressible flow CFD model and $\dot{\mathrm{m}}_{\mathrm{M}}(\mathrm{t})$ obtained from a compressibility correction on the $\dot{\mathrm{m}}_{\mathrm{Inc|OM} 1}(\mathrm{t})$ values - which are obtained from an incompressible CFD model 
Figure 17: The geometry for the two devices (orifice meter and nozzle) that are merged together, with proper instruments, and placed between points $L$ and $O$ of Fig. 1 .........46

Figure 18: Pressure difference plot for new inlet geometry and a primary driving frequency of $3 \mathrm{~Hz}$

Figure A-1: Raw mass flow rate results for the new inlet geometry

Figure A-2: Alpha corrected mass flow rates for the new inlet geometry .....

Figure A-3: FFT magnitude plot of the alpha corrected mass flow rate data shown in Fig. A-2 55

Figure A-4: Measured and computed pressure difference across the orifice meter and nozzle of the new geometry for a representative $10 \mathrm{~Hz}$ LA case...... 55

Figure A-5: The proposed direct validation experimental flow-loop 58 


\section{List of Tables}

Table 1: Mesh independence testing results for steady state inlet pressures...............21

Table 2: Steady state values and fluid properties for experimental runs, along with

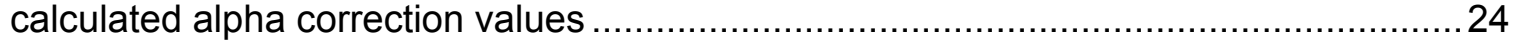

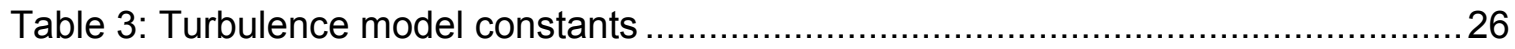

Table 4: Orifice-meter OM1 and orifice-meter OM2 Input Data ................................. 37

Table 5: Orifice-meter OM1 and orifice-meter OM2 Output Data................................ 37

Table A-1: Grid independence results for the new inlet geometry ............................52 


\section{Preface}

This thesis titled "Assessments and Computational Simulations in Support of a Time-Varying Mass Flow Rate Measurement Technique for Pulsatile Gas Flow" is to contribute to further development of an orifice meter for use in obtaining time-varying mass flow measurements.

This thesis accomplishes the following: It takes preliminary incompressible Computational Fluid Dynamics (CFD) modeling plus experimental synthesis approach and refines it to have significant confidence in the measurement approach. Preliminary incompressible CFD (with errors) were conducted by an earlier MS student on the project, N. Ajotikar. Preliminary experiments were done by M. Kivisalu. My work is to: (i) repeat and carry forward an accurate incompressible CFD simulation for the current geometry (referred to as OM1 and OM2), as well as to contribute to the better understanding of the measured approach. (ii) To propose a verification approach involving new experimental geometry (OM1 and nozzle) and corrective simulations. (iii) To assist in the implementation of compressible correction application of our team (an analytical approach by Dr. Narain and implemented by M. Zhao) as well as a compressible CFD approach from M. Zhao [1]. Therefore, Sections 3.4.1, 3.4.2 of this thesis draw heavily on material from [1-2] and are included here for continuity, while Sections 3.1, 3.2, 3.3, 3.4.3, 3.4.4 and Appendix A-1 presented here were primarily completed by myself and are further expanded on from previously published material.

As a result of the above, I have made a significant contribution (as a co-author) of the relevant JFE paper, Narain et al. [2]. Therefore, parts of this thesis report will overlap with content of this paper [2]. 


\section{Acknowledgements}

I would like to thank my advisor, Dr. Amitabh Narain for his support and guidance throughout my time on the research team.

I would also like to thank the research and experimental team here at Michigan Tech including: Michael Kivisalu, Patcharapol Gorgitrattanagul, Ranjeeth Naik, Menghan Zhao, and Nikhil Shankar.

This paper and its supporting materials would not have been possible without the support provided in part by NASA Grant NNX10AJ59G and NSF Grant CBET1033591.

\section{Nomenclature}

\section{Accent Notations}

$\overline{\mathrm{X}}: \quad$ Time-averaged value of variable ' $\mathrm{X}(\mathrm{t})$ '

$\mathrm{X}^{\prime} \quad$ Fluctuations in variable ' $\mathrm{X}(\mathrm{t})$ ' with $\mathrm{X}(\mathrm{t}) \equiv \overline{\mathrm{X}}+\mathrm{X}^{\prime}(\mathrm{t})$

$a_{x}(f): \quad$ Amplitude at frequency $f$ in the FFT of variable ' $X(t)$ '

$\overline{\mathrm{X}}_{\mathrm{L}}$ : $\quad$ Time-averaged value of variable ' $\mathrm{X}_{\mathrm{L}}(\mathrm{t})$ ' at cross-section ' $\mathrm{L}$ '

$\mathrm{X}_{\mathrm{L}}^{\prime}$ : $\quad$ Fluctuations in variable ' $\mathrm{X}_{\mathrm{L}}(\mathrm{t})$ ' at cross-section ' $\mathrm{L}$ ' with $\mathrm{X}_{\mathrm{L}}(\mathrm{t}) \equiv \overline{\mathrm{X}}_{\mathrm{L}}+\mathrm{X}_{\mathrm{L}}^{\prime}(\mathrm{t})$

$a_{X-L}(f)$ : Amplitude at frequency $f$ in the FFT of variable $X_{L}^{\prime}(t)$

Labels

$\mathrm{F}_{\mathrm{C} 1}$ : Coriolis mass flow meter 1

$\mathrm{F}_{\mathrm{C} 2}$ : $\quad$ Coriolis mass flow meter 2

om: Generic orifice-plate flow meter. Also used as a variable subscript.

OM1: Orifice-plate meter 1. Also used as a device specific subscript.

OM2: Orifice-plate meter 2. Also used as a device specific subscript. 


\section{$\underline{\text { Variables }}$}

$\mathrm{c}_{0}$ : Acoustic velocity of vapor flowing through orifice meter $[\mathrm{m} / \mathrm{s}]$

f: $\quad$ Frequency $[\mathrm{Hz}]$

$f_{p}$ : Primary driving frequency for pulsatile flow $[\mathrm{Hz}]$

$f_{F}: \quad$ Highest frequency of interest for pulsatile flow $[\mathrm{Hz}]$

g: Gravitational field vector within an orifice meter $\left[\mathrm{m} / \mathrm{s}^{2}\right]$

k: $\quad$ Empirical orifice meter constant defined in section $2\left[\mathrm{~kg} / \mathrm{m}^{7}\right]$

$k$ : $\quad$ Symbol used for kinetic energy fluctuations in the $k-\varepsilon$ turbulence model

$\mathrm{k}_{\mathrm{t}}$ : Eddy thermal conductivity in Eq. (30) and in the Appendix

L: $\quad$ Empirical orifice meter constant defined in section $2\left[\mathrm{~kg} / \mathrm{m}^{4}\right]$

$\dot{\mathrm{m}}(\mathrm{t})$ : Time-varying mass flow rate $[\mathrm{g} / \mathrm{s}]$

$\dot{\mathrm{m}}_{\mathrm{L}}(\mathrm{t})$ : Time-varying mass flow rate at cross-section $\mathrm{L}[\mathrm{g} / \mathrm{s}]$

$\Delta \dot{\mathrm{m}}_{\mathrm{L}}(\mathrm{t})$ : Compressibility correction for mass flow rate at cross-section $\mathrm{L}[\mathrm{g} / \mathrm{s}]$

$\mathrm{p}_{0}: \quad$ Reference pressure $[\mathrm{kPa}]$

p: Absolute physical pressure in Eq. (5) [KPa]

$\mathrm{p}_{\mathrm{CFD}}$ : Pressure field in the computational model $[\mathrm{kPa}]$

$\mathrm{p}_{\text {off }}^{\prime}: \quad$ Offset pressure $\left(\mathrm{p}_{\text {off }}^{\prime} \equiv \mathrm{p}-\mathrm{p}_{0}\right)[\mathrm{kPa}]$

nd- $\mathrm{p}_{\text {off }}^{\prime}$ : Non-dimensional offset pressure $\mathrm{p}_{\text {off }}^{\prime}$

$\Delta \mathrm{p}_{\mathrm{om}}$ : Pressure-difference across orifice meter device 'om' [Pa]

$\Delta \mathrm{p}_{\mathrm{MN}}$ : Pressure-difference between locations ' $\mathrm{M}$ ' and ' $\mathrm{N}$ ' [Pa]

Q: Volume flow rate $\left[\mathrm{m}^{3} / \mathrm{s}\right]$

$\mathrm{r}$ : Radius within the orifice meter duct [m]

$\mathrm{t}: \quad$ Time $[\mathrm{s}]$

$\mathrm{T}$ : $\quad$ Time period of averaging for mean flow variable values $\left(T>>\Delta \mathrm{t}_{\mathrm{c}}\right)[\mathrm{s}]$ 
$\Delta \mathrm{t}_{\mathrm{c}}: \quad$ Time scale of pulsations $\left(\Delta \mathrm{t}_{\mathrm{c}} \equiv 1 / \mathrm{f}_{\mathrm{P}}\right)[\mathrm{s}]$

v: $\quad$ Flow velocity vector within an orifice meter $[\mathrm{m} / \mathrm{s}]$

$\mathrm{x} \quad$ Distance from the upstream pressure tap of an orifice meter [m]

$\mathbf{x} \quad$ Position vector within an orifice meter [m]

\section{Greek Symbols}

$\alpha$ Empirical correction factor proposed for unsteady turbulent CFD solutions of pulsatile flows [-]

$\mu_{0}: \quad$ Reference viscosity $[\mathrm{kg} / \mathrm{m} \cdot \mathrm{s}]$

$\rho_{\mathrm{i}}$ : $\quad$ Density at location 'i' $\left[\mathrm{kg} / \mathrm{m}^{3}\right]$

$\rho_{0}: \quad$ Reference density $\left[\mathrm{kg} / \mathrm{m}^{3}\right]$

$\phi_{X}(f): \quad$ Phase at frequency $f$ in the FFT of variable ' $X(t)$ ' [radians]

$\phi_{X^{\prime}-L}(f):$ Phase at frequency $f$ in the FFT of variable $\mathrm{X}_{\mathrm{L}}^{\prime}(\mathrm{t})$ [radians]

\section{Subscripts}

\section{Locations / Devices}

D: Downstream pressure tap location for a generic orifice-plate meter

FC: Generic Coriolis mass flow meter

L: $\quad$ Upstream pressure tap location for orifice meter OM1

M: Downstream pressure tap location for orifice meter OM1

$\mathrm{N}$ : $\quad$ Upstream pressure tap location for orifice meter OM2

O: $\quad$ Downstream pressure tap location for orifice meter OM2

U: $\quad$ Upstream pressure tap location for a generic orifice-plate meter

\section{Conditions}

CFD-I|om: Associated with the raw output from an incompressible unsteady turbulent CFD model for orifice-meter "om" 
Inclom: Associated with the empirically corrected output from an incompressible unsteady turbulent CFD model for orifice-meter "om"

stored: Associated with mass stored in the orifice meter control volume within the time period $\Delta \mathrm{t}_{\mathrm{c}}$ 


\section{Abstract}

This thesis covers the correction, and verification, development, and implementation of a computational fluid dynamics (CFD) model for an orifice plate meter. Past results were corrected and further expanded on with compressibility effects of acoustic waves being taken into account. One dynamic pressure difference transducer measures the time-varying differential pressure across the orifice meter. A dynamic absolute pressure measurement is also taken at the inlet of the orifice meter, along with a suitable temperature measurement of the mean flow gas. Together these three measurements allow for an incompressible CFD simulation (using a well-tested and robust model) for the cross-section independent time-varying mass flow rate through the orifice meter. The mean value of this incompressible mass flow rate is then corrected to match the mean of the measured flow rate( obtained from a Coriolis meter located up stream of the orifice meter). Even with the mean and compressibility corrections, significant differences in the measured mass flow rates at two orifice meters in a common flow stream were observed. This means that the compressibility effects associated with pulsatile gas flows is significant in the measurement of the time-varying mass flow rate. Future work (with the approach and initial runs covered here) will provide an indirect verification of the reported mass flow rate measurements. 


\section{Introduction}

The orifice-plate meter is a device in which a differential pressure $\left(\Delta \mathrm{p}_{\mathrm{OM}}\right)$ is measured across two ports in a flow stream. Between these two points is an orifice-plate which causes a flow restriction and significant pressure drop. The method described here requires that this differential pressure be a dynamic (time-varying) reading, along with at least one dynamic absolute pressure measurement (suitably located within the orifice meter geometry). In addition, a steady state, time-averaged mass flow rate measurement is needed from a separate device (e.g. a Coriolis meter) and a mean representative temperature measurement is needed to characterize the gas/vapor flow. While this arrangement (of both orifice meter and Coriolis meter) has been thoroughly verified for a steady flow, the findings in [2] (and expanded on here) show that with suitable CFD and additional measurements, this device may also provide the timevarying mass flow rate.

\subsection{Inadequacy of Existing Approaches in Measuring the Pulsatile Mass Flow Rate}

Earlier efforts [3-7] have focused primarily on measuring the mean value of the time-varying mass flow rate $\overline{\mathrm{m}}$ associated with pulsatile flows. These approaches limited themselves to computing the various time-averaged mean values of the dynamic pressure-difference data $\Delta \mathrm{p}_{\mathrm{om}}(\mathrm{t})\left(\overline{\mathrm{p}}_{\mathrm{om}}, \overline{\sqrt{\Delta \mathrm{p}^{2}}}\right.$ om , etc. in [3]) (mean values denoted by over bars) for the orifice-plate meter and proposed methods for relating the computed mean values to the determination of the mean volume flow rate $\bar{Q}$ or mass flow rate $\overline{\mathrm{m}} \equiv \rho_{0} \cdot \overline{\mathrm{Q}}$ (where $\rho_{0}$ is the constant mean value of gas density). All these works recognized that, because of inertia effects, the mean flow rate $\bar{Q}$ is not the same as the one associated with steady incompressible flows under steady imposition of the same 
mean pressure-difference $\overline{\Delta \mathrm{p}}_{\mathrm{om}}$. This value is different for pulsatile flows (high-amplitude fluctuations) than for steady flows or quasi-steady flows (with negligible or low-amplitude content in $\Delta \mathrm{p}_{\mathrm{om}}^{\prime}(\mathrm{t})$ fluctuations). Further proof of this inadequacy is shown in [2]. 


\section{Experimental Procedures and Equipment \\ (Common between this thesis and [1])}

\subsection{Experimental System and Procedures}

The flow-loop used in these experiments is shown in Fig. 1. For these experiments, heat was supplied to the pool boiler at a constant load causing a steady vapor flow of FC-72 to travel through the Coriolis mass flow meter $\mathrm{F}_{\mathrm{C} 1}$. A pulsator directly downstream of the Coriolis meter then imposes pressure fluctuations on the vapor flow. The pulsator used in the experiments here is a diaphragm displacement compressor whose suction and pressure sides have been joined together by removing the values in the manifolds. This causes the diaphragm in the compressor to retain its primary oscillations, all while ensuring that there is not an effect on the mean mass flow rate within the flow loop. The frequency of the imposed pulsations is controlled by varying the motor's speed, while the amplitude of the pulsations is controlled by the valve $\mathrm{V}_{0}$.

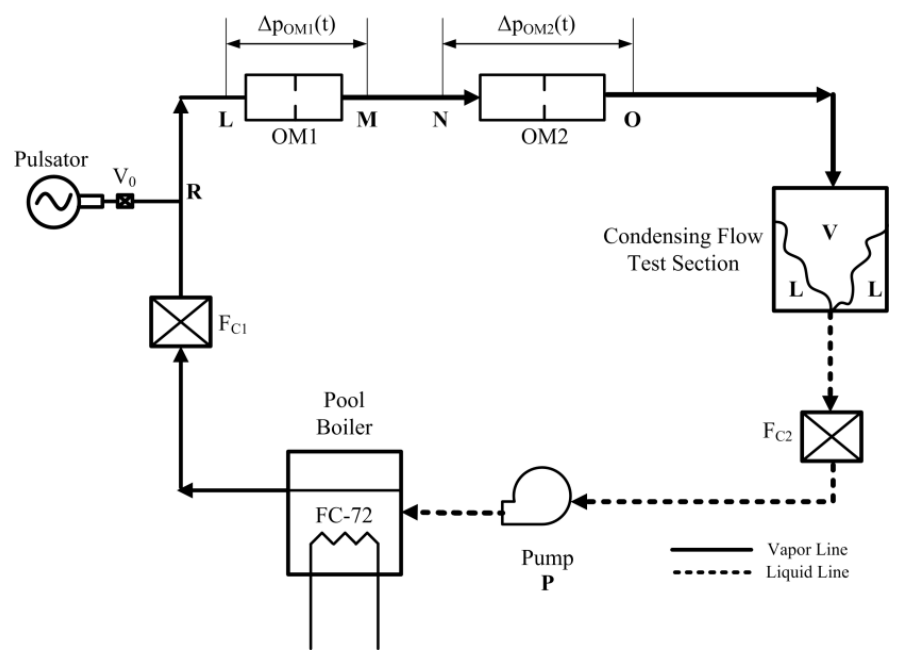

Figure 1: Full flow loop schematic with OM1 and OM2 shown

After the imposed pulsations, the vapor flows through orifice meter OM1 and orifice meter $\mathrm{OM} 2$ before entering the test channel. While this surface could be heated 
or cooled to study both condensing and boiling flows [8], for these experiments, it was only kept slightly (approx. $5-10{ }^{\circ} \mathrm{C}$ ) above saturation temperature. The vapor then flowed out of the test channel and into the vertical tube condenser before being pumped back into the pool boiler. The working fluid for these experiments was selected to be FC72 , an electronic cooling refrigerant provided by $3 \mathrm{M}$. This fluid was chosen for its low saturation pressure and that it can be safely handled within the lab. It should be noted that FC-72 vapor cannot be modeled as an ideal gas under the conditions here; however, this proposed methodology will still work under common flow conditions.

\section{$\underline{2.2 \text { Instrumentation and Data Acquisition }}$}

A National Instruments ( $\mathrm{NI})$ data acquisition system is used to gather data and control feedback loops on the flow controls. The primary program runs at a data collection rate of approximately $1 \mathrm{~Hz}$ while the dynamic data sub program collects at a rate of $2000 \mathrm{~Hz}$ in 5 second increments. During the runs presented in this paper, 20 minute blocks of steady state data $($ at $1 \mathrm{~Hz})$ were taken for each condition. During this time 10 dynamic data blocks were taken. Then a suitable block was selected and used in the further computations and calculations presented here. The steady state values were averaged across the 20 minute block.

The absolute pressure readings in the orifice meter and surrounding geometry were taken with Omega Engineering absolute pressure transducers. For the runs presented here, one transducer was located at the inlet of the orifice meter OM1 (point $M$ of Fig.1) and another at the exit (point $L$ of Fig. 1) to capture dynamic readings at each location. The accuracy of these transducers is $\pm 0.5 \mathrm{kPa}$ after calibration. Validyne Inc. differential pressure transducers were used to gather the dynamic pressure difference across both of the orifice meters. The accuracy of these transducers after calibration is $\pm 20 \mathrm{~Pa}$. In order to calculate vapor properties (density and viscosity) in the orifice meter 
and nozzle, T-type thermocouples were used to measure the approximate flow temperature. There were two thermocouples located in the test section, the first at the inlet of the OM1 and the second at the exit of the OM1. Both are accurate within $\pm 1{ }^{\circ} \mathrm{C}$ after calibration. Their readings were averaged over the 20 minute runs and then averaged between each other to find the average properties for the constant density assumption used in the simulation.

The mean mass flow rate of both the vapor and liquid in the flow loop was measured by two Elite model CMF010 Coriolis meters from Micro-Motion Inc. The accuracy of the vapor Coriolis meter is $\pm 0.0037 \mathrm{~g} / \mathrm{s}$ and the accuracy of the liquid Coriolis meter is $\pm 0.0010 \mathrm{~g} / \mathrm{s}$. The vapor Coriolis meter was located above the pool boiler and directly before the pulsator, while the liquid Coriolis meter is located after the constant displacement pump and before the pool boiler. By measuring the mean mass flow rate at two locations in the flow loop, it is possible to achieve and ensure that the mean mass flow rate is constant throughout each 20 minute run. It should be noted that only one Coriolis meter (or any other mean mass flow rate measurement) is needed and for the runs reported here the vapor mass flow rate was used. As shown in $[9,10,11]$, a Coriolis meter is well capable of measuring the mean mass flow rate $\overline{\dot{m}}$ of a pulsatile gas flow.

Both of the orifice meters used are custom designed and assembled in house at Michigan Tech. Detailed drawings of their geometries and instrumentation locations of shown in Fig. 2 for OM1 and Fig. 3 for OM2. 


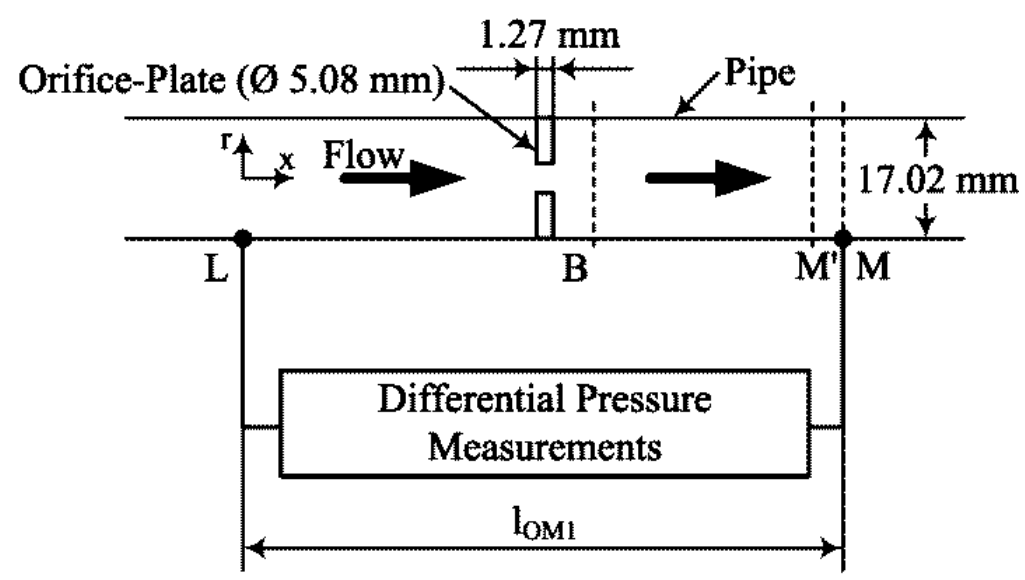

Figure 2: Detailed drawing of OM1 with loM $1=127 \mathrm{~mm}$

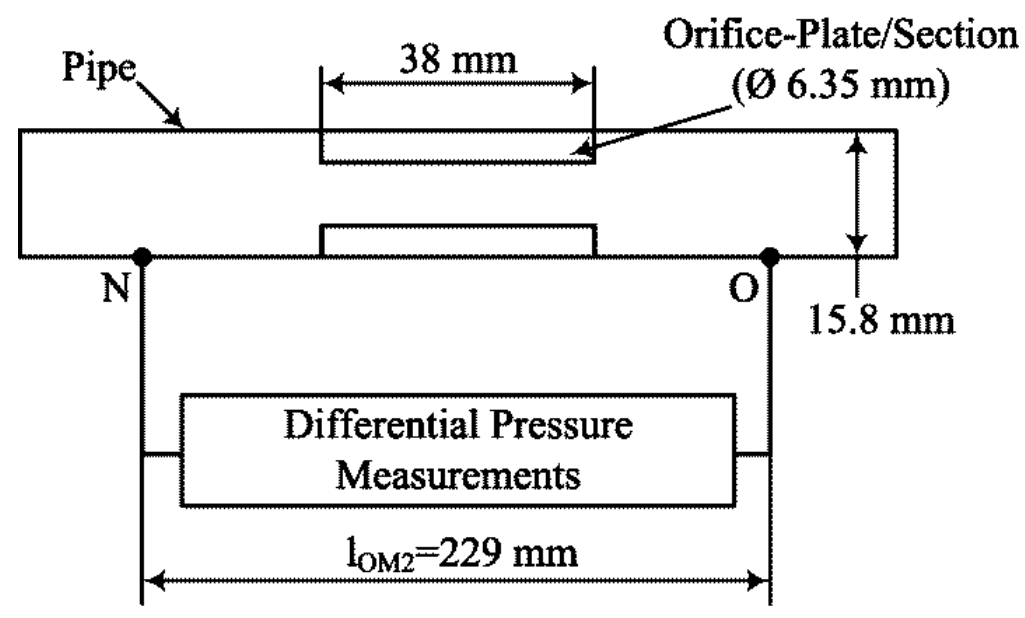

Figure 3: Detailed drawing of OM2 


\section{Methods}

\section{$\underline{3.1 \text { Mesh Construction and Verification }}$}

To improve on past simulations and streamline future work, the previous CFD models which used a different collection of software including Gambit (to create the geometry and mesh) and Fluent (to set-up and solve the problem) were replaced with one model in Ansys Workbench 13.0. This new software allows for the entire process from geometry definition to post processing of results to be completed in one software package. In addition, once the simulation model is constructed, it may also be solved within stand-alone editions of Fluent.

\subsubsection{Spatial Grid Independence}

To validate this new model and associated geometry, various mesh sizes were tested for a range of flow conditions and solver conditions to insure a robust model. The size of the mesh was varied from $1.0 \mathrm{e}-4 \mathrm{~m}$ to $8.0 \mathrm{e}-2 \mathrm{~m}$ for the orifice meter geometry. The full inlet and nozzle models (discussed in Appendix A-1) were tested over a reduced range of $1.0 \mathrm{e}-4 \mathrm{~m}$ to $8.0 \mathrm{e}-4 \mathrm{~m}$ as this was the best quality range found in the OM mesh tests. Each of the geometries was meshed with quadrilateral mesh elements and the size allowed to vary as per the software requirements. The respective maximum cell counts for the nine meshes considered are given in Table 1.

Table 1: Cell sizes and mesh counts for different mesh configurations

\begin{tabular}{|c|c|c|}
\hline $\begin{array}{c}\text { Mesh } \\
\text { Configuration }\end{array}$ & $\begin{array}{c}\text { Maximum Cell } \\
\text { Size }(\mathbf{m})\end{array}$ & Element Count \\
\hline Mesh 1 & 0.00008 & 168534 \\
\hline Mesh 2 & 0.0001 & 107344 \\
\hline Mesh 3 & 0.0002 & 27104 \\
\hline Mesh 4 & 0.0004 & 9250 \\
\hline Mesh 5 & 0.0008 & 2829 \\
\hline Mesh 6 & 0.008 & 864 \\
\hline Mesh 7 & 0.005 & 569 \\
\hline Mesh 8 & 0.01 & 325 \\
\hline Mesh 9 & 0.08 & 145 \\
\hline
\end{tabular}




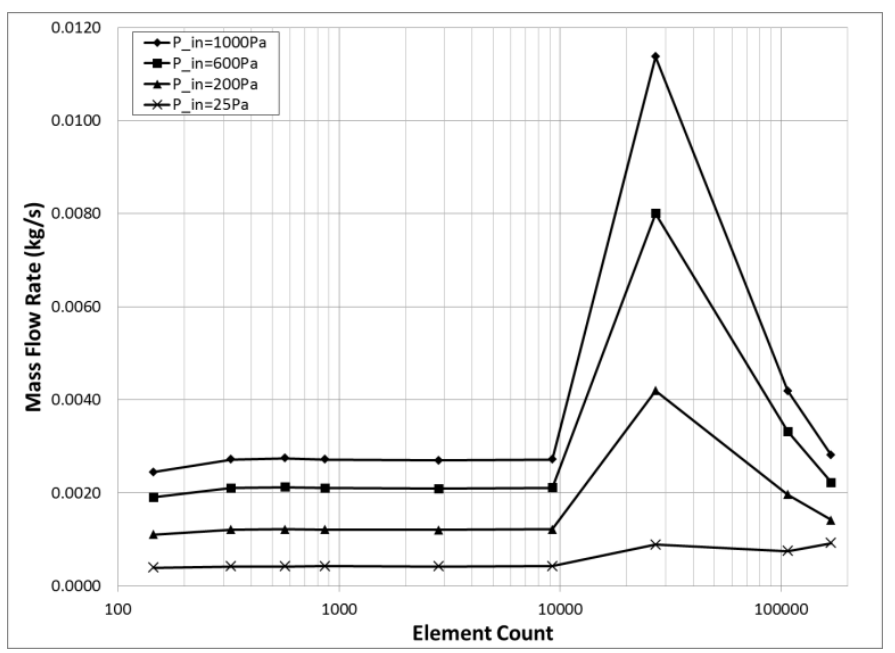

Figure 4: Steady state mass flow rates for varying mesh sizes

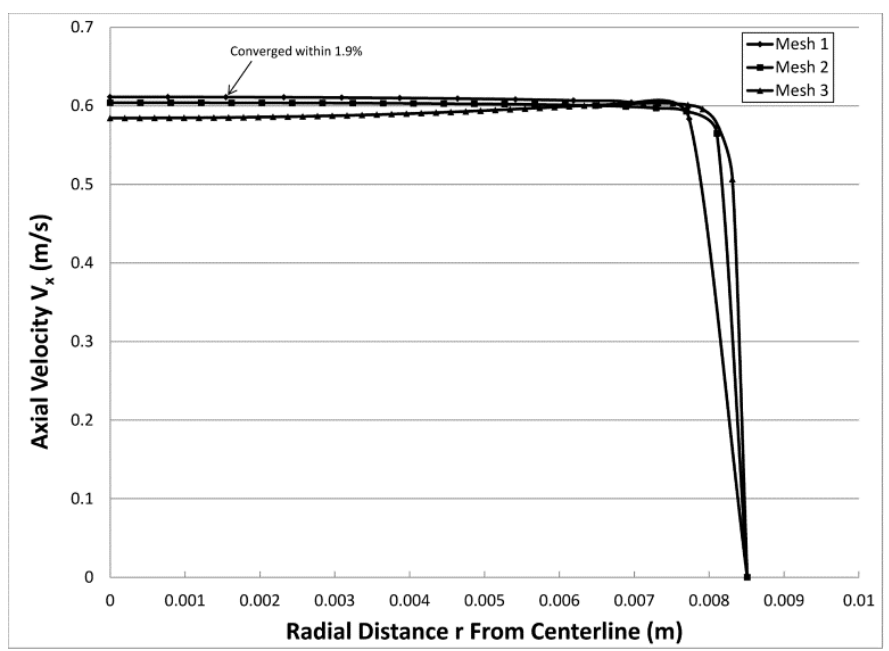

Figure 5: Velocity profiles at $x=0.12 m$ and $t=0.8235$ seconds for three mesh sizes

Spatial grid independent results were obtained for all the runs. For initial grid testing, a steady state case was used to determine the steady in the time mass flow rate though the orifice meter for various pressures. The pressure difference was tested over a range of $25-1000 \mathrm{~Pa}$ (specifically $1000 \mathrm{~Pa}, 600 \mathrm{~Pa}, 200 \mathrm{~Pa}$, and $25 \mathrm{~Pa}$ ). The steady state solutions of the mass flow rate at the inlet were then plotted against the element count as shown in Fig. 4. In order to best select the mesh size, several factors were 
considered including, computation time, accuracy and reproducibility. To accurately capture the wall conditions and effects in turbulent flow the Fluent User's Guide [12] recommends that a minimal of six elements be used across any opening.

Further unsteady testing was done on Meshes 3-5 and is shown here for a representative unsteady flow associated with run 3 in discussed in Section 3.4. The gridindependence is shown with the help of computed values of the axial component of velocity $V_{x}(x, r, t)$. Fig. 5 shows the velocity profiles $V_{x}(x, r, t)$ at the location $x=0.12 m$ and $t=0.8235 \mathrm{~s}$ (of the measured pressure signal in Fig. 6) for the three meshes (Mesh 3-5) of Table 1. The results in Fig. 5 show that spatial grid independence was achieved within $2 \%$ of each other for Mesh 4 and Mesh 5 in Table 1.

Therefore either of these meshes (Mesh 4 was chosen) can be used. Also, amongst all of the meshes tested, Mesh 4 has the balance between minimal cell count (which is desirable to avoid unacceptably large computational time for the long unsteady runs) and accurate satisfaction of the restrictions imposed by the wall functions. In fact Mesh 4 worked for CFD analyses of all the pulsatile cases in discussed in Section 3.4.

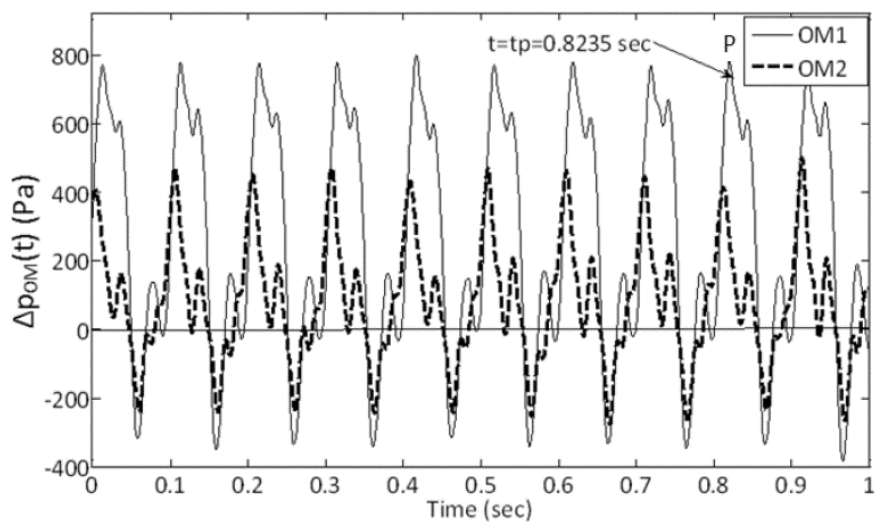

Figure 6: Pressure difference signal in the time domain for Case 3 of Table 4 


\subsubsection{Time Step Independence}

In addition to grid independence, unsteady CFD solutions must also be tested for time step independence. The selections of representative time-steps are made on the basis of the need to resolve the predominant frequency present in the differential pressure transducer measurement across the geometry of interest. The data acquisition rate (i.e. DAQ rate) of $2000 \mathrm{~Hz}$ for the differential pressure transducers was such that the data was acquired at the interval of $0.0005 \mathrm{sec}$ and the acquired data was made continuous by linear interpolation between these discrete time-intervals. It is found that this same time-step size $\left(\Delta \mathrm{t}_{2}\right)$ of $0.0005 \mathrm{sec}$ for unsteady CFD simulations is adequate for all cases $\left(f_{P} \leq 10 \mathrm{~Hz}\right)$ considered in this paper. By employing one larger time-step $\Delta t_{1}$ and two smaller time steps $\Delta \mathrm{t}_{3}$ and $\Delta \mathrm{t}_{4}$ (that were fractions of the time-step $\Delta \mathrm{t}_{2}$ ), it was verified that the unsteady CFD solution is approximately time-independent and accurate. Table 2 lists the four time step sizes used for this study.

Table 2: Chosen time-step sizes

\begin{tabular}{|c|c|}
\hline Configuration & $\begin{array}{c}\text { Time Step } \\
\text { Size (sec) }\end{array}$ \\
\hline TS $1\left(\Delta \mathrm{t}_{1}\right)$ & 0.001 \\
\hline TS $2\left(\Delta \mathrm{t}_{2}\right)$ & 0.0005 \\
\hline TS $3\left(\Delta \mathrm{t}_{3}\right)$ & 0.00025 \\
\hline TS $4\left(\Delta \mathrm{t}_{4}\right)$ & 0.0001 \\
\hline
\end{tabular}

For the unfiltered $\Delta \mathrm{p}_{\mathrm{OM} 1}(\mathrm{t})$ data in Fig. 6 and Mesh 4 of Table 1, four different transient solutions were obtained for the four different time step sizes in Table 2. The solutions' axial component of the velocity profile at the time instant of $t=0.8235$ seconds (see Fig. 6) and at the location $\mathrm{x}_{\mathrm{M}^{\prime}}=0.120 \mathrm{~m}$ (see Fig. 2) are plotted in Fig. 7. It is clear from Fig. 7 that for all the four different time step sizes, the velocity profiles are the same (within $1 \%$ of one another). This indicates that the time step $\Delta t_{2}$ of $0.0005 \mathrm{sec}$ is good for 
accurately predicting the unsteady solutions. Therefore, unless otherwise indicated, all the subsequent simulations employ the time step size of $0.0005 \mathrm{sec}$ and quadrilateral mesh given by Mesh 4 in Table 1.

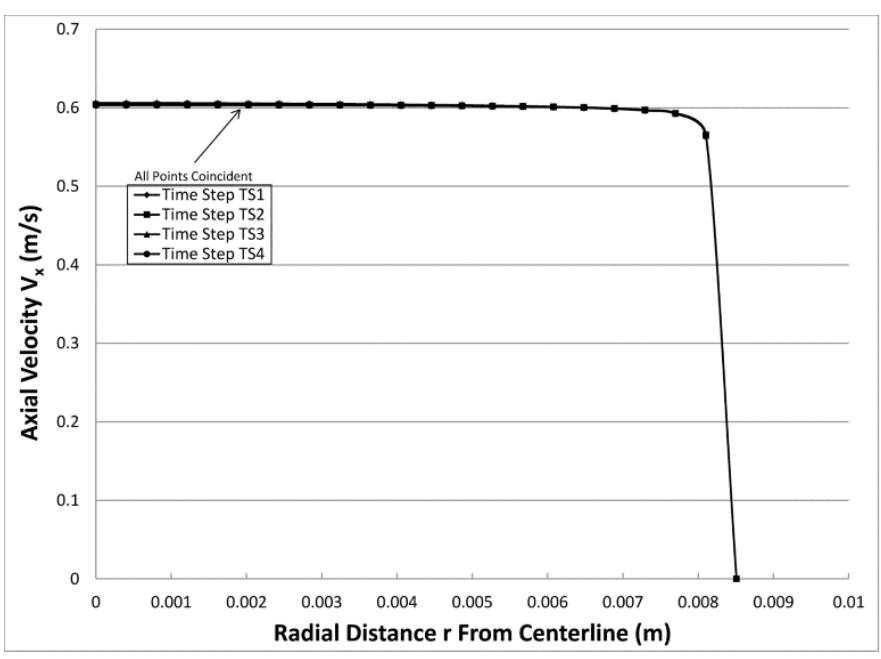

Figure 7: Axial Velocity at $x=0.12 \mathrm{~m}$ and $\mathrm{t}=0.8235$ seconds for different Time Steps

\subsubsection{Turbulence Model and Solver Settings}

The range of Reynolds number $(\mathrm{Re})$ based on OM1's outer tube diameter of $16.97 \mathrm{~mm}$ (not the orifice diameter of $5.08 \mathrm{~mm}$ ) and the mean flow rate was $7600<\mathrm{Re}$ $<15000$; this is the turbulent flow regime for a pipe. The large amplitudes at imposed frequencies $1 \leq \mathrm{f}_{\mathrm{P}} \leq 30 \mathrm{~Hz}$ keep the unsteady flow turbulent. For a few cases, instantaneous Reynolds number may go below the critical number (about 2100) for steady flows. However peak instantaneous Reynolds numbers are high enough to keep the flows turbulent by preventing any re-laminarization tendency associated with the few cases' very short time durations for which the instantaneous $\operatorname{Re}<2100$. For the standard k- $\varepsilon$ turbulence model described in [12], the default values of model constants were used and are listed in Table 3. Similarly, for the Reynolds Stress model [12], the employed model constants are also listed in Table 3. Both models used standard wall 
functions for the near wall treatment. The results of turbulence model testing is further discussed in Section 3.3.1.

Table 3: Turbulence Model Constants

\begin{tabular}{|c|c|c|c|c|c|c|}
\hline Model & Cmu & $\begin{array}{c}\text { C1- } \\
\text { Epsilon }\end{array}$ & $\begin{array}{c}\text { C2- } \\
\text { Epsilon }\end{array}$ & $\begin{array}{c}\text { TKE PrandtI } \\
\text { Number }\end{array}$ & $\begin{array}{c}\text { TDR PrandtI } \\
\text { Number }\end{array}$ & C1-PS \\
\hline $\begin{array}{c}\mathrm{k}-\varepsilon(2 \\
\text { eqns. }\end{array}$ & 0.09 & 1.44 & 1.92 & 1.0 & 1.3 & -- \\
\hline $\begin{array}{c}\text { Reynolds } \\
\text { Stress }\end{array}$ & 0.09 & 1.44 & 1.92 & -- & -- & 1.8 \\
\hline
\end{tabular}

\subsection{Empirical Corrections for the Mean Mass Flow Rate}

It has been proposed [2] that even small model-dependent quantitative variations from the experimental measurements or CFD solver can be removed and model independent values of $\dot{\mathrm{m}}_{\mathrm{CFD}-\mathrm{I} \mid \mathrm{om}}(\mathrm{t})$, denoted as $\dot{\mathrm{m}}_{\mathrm{Inc|om}}(\mathrm{t})$, be obtained with the help of an empirical correction factor $\alpha$ (which is computed for each flow case) through the following defining relationship:

$$
\dot{\mathrm{m}}_{\text {Inc|om }}(\mathrm{t})=\alpha \cdot \dot{\mathrm{m}}_{\mathrm{CFD}-\mathrm{I} \mid \mathrm{om}}(\mathrm{t})
$$

Furthermore it is proposed that for each pulsatile flow realization, the unknown $\alpha$ in Eq. (1) be obtained from the requirement that the long-term time-averaged values of the resulting mean mass flow rate $\dot{\mathrm{m}}_{\text {Inc|om }}(\mathrm{t})$ must equal the experimentally measured (by a representative flow meter such as those shown in Fig. 8 ) value $\overline{\dot{m}}_{\mathrm{FC}}$. 


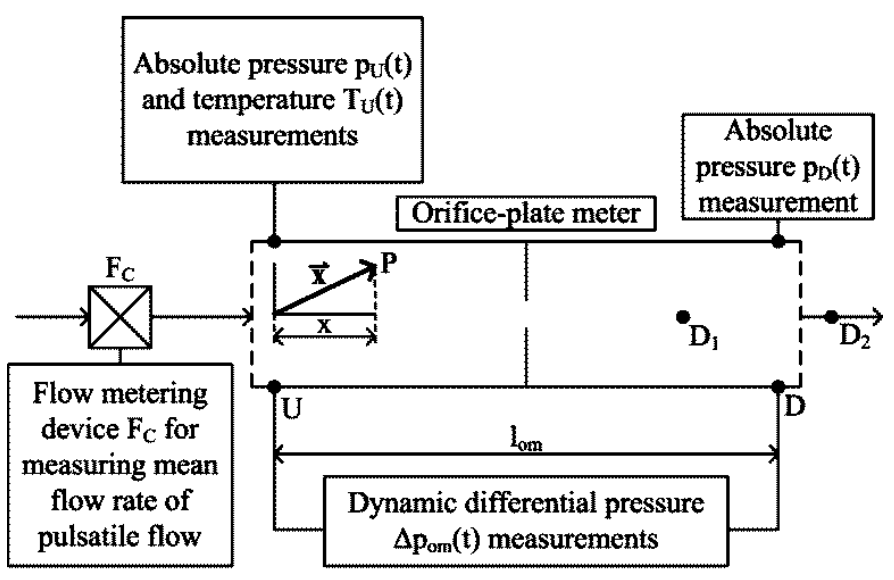

Figure 8: Representative Orifice Meter with instruments

For this, time-average $\overline{\dot{\mathrm{m}}}_{\mathrm{CFD}-\mathrm{I} \mid \mathrm{om}}=\frac{1}{\mathrm{~T}} \int_{\mathrm{t}_{0}}^{\mathrm{t}_{0}+\mathrm{T}} \dot{\mathrm{m}}_{\mathrm{CFD}-\mathrm{I} \mid \mathrm{om}}(\mathrm{t}) \cdot \mathrm{dt}$ is obtained from the computationally known time-varying mass flow rate $\dot{\mathrm{m}}_{\mathrm{CFD}-\mathrm{I} \mid \mathrm{om}}(\mathrm{t})$ values, by choosing averaging durations $T>1 / f_{P}$ in a way that it makes the averages independent of the choice of $T$ and $t_{0}$. Next it is required that the time-average $\overline{\dot{\mathrm{m}}}_{\text {Inc|om }}=\frac{1}{\mathrm{~T}} \int_{\mathrm{t}_{0}}^{\mathrm{t}_{0}+\mathrm{T}} \dot{\mathrm{m}}_{\text {Inc|om }}(\mathrm{t}) \cdot \mathrm{dt}$ satisfies:

$$
\overline{\dot{\mathrm{m}}}_{\mathrm{Inc} \mid \mathrm{om}}=\overline{\dot{\mathrm{m}}}_{\mathrm{FC}}
$$

When the long time average of Eq. (1) itself is taken and the requirement in Eq. (2) is enforced, one obtains the value of $\alpha$ as:

$$
\alpha=\frac{\overline{\mathrm{m}}_{\mathrm{FC}}}{\overline{\mathrm{m}}_{\mathrm{CFD}-\mathrm{I} \mid \mathrm{om}}}
$$

\section{$\underline{3.3 \text { Incompressible and Isothermal Model Approach }}$}

It is first assumed that acoustic waves and their reflections, caused by fluctuations in the absolute and differential pressures $\left(p_{u}(t)\right.$ and $\Delta p_{o m}(t)$ in Fig. 8), lead to density and time-rate of density variations whose effects within the orifice-meter can 
be ignored. Then, assuming $\rho \cong \rho_{0}$, the instantaneous inlet pressure at point $U(x=0$ in Fig. 8 ) is set to be the measured pressure-difference $\Delta \mathrm{p}_{\mathrm{om}}(\mathrm{t})$, and the exit pressure at point $D\left(x=I_{o m}\right.$ in Fig. 8) is set to be zero at all times. In addition, steady no-slip velocity boundary conditions are assumed to hold at the walls. Besides constancy of density, it is reasonable to assume that temperature variations (if any) are not large enough to significantly affect molecular or eddy viscosity from their respective isothermal (mean flow temperature) values. Hence the isothermal assumption will work even if there are small temperature variations in the flow field. Therefore, a converged CFD solution (on FLUENT) is obtained for the unsteady, incompressible, turbulent, and isothermal flow problem described below. For the aforementioned geometry and boundary conditions, the CFD approach solves for velocity field $\mathbf{v}$ and computational pressure field $\mathrm{p}_{\mathrm{CFD}}$ at any time $t \geq 0$ and any location $\overrightarrow{\mathbf{x}}$ within the specified orifice-meter geometry of Fig. 8 . The following governing equations [12-15] are solved:

$$
\begin{gathered}
\operatorname{div}\left(\rho_{0} \mathbf{v}\right)=0 \\
\text { and } \\
\rho_{0}\left[\frac{\partial \mathbf{v}}{\partial \mathrm{t}}+(\mathbf{v} \cdot \nabla \mathbf{v})\right]=-\nabla \mathrm{p}_{\mathrm{CFD}}+\rho_{0} \mathbf{g}+\operatorname{div}\left[\mu_{\mathrm{t}}\left\{\nabla \mathbf{v}+\nabla \mathbf{v}^{\mathrm{T}}\right\}\right],
\end{gathered}
$$

where $\mu_{\mathrm{t}}$ is the eddy viscosity (for isothermal turbulent flows) in the standard $\mathrm{k}-\varepsilon$ model [14-17]. For the Reynolds Stress Model, the term " $\operatorname{div}\left[\mu_{\mathrm{t}}\left\{\nabla \mathbf{v}+\nabla \mathbf{v}^{\mathrm{T}}\right\}\right]$ " on the right side of the momentum balance in Eq. (4) is replaced by appropriate terms [12-15]. The initial conditions (at $t=-\varepsilon$ for some $\varepsilon>0$ ) for solving Eq. (4) come from the solution of the steady problem (without pressure boundary condition fluctuations over the mean $\overline{\Delta \mathrm{p}}_{\mathrm{om}}$ ), and unsteady $\Delta \mathrm{p}_{\mathrm{om}}(\mathrm{t})$ values are imposed only for $\mathrm{t}>-\varepsilon$. The fluctuations present in the experimental $\Delta \mathrm{p}_{\mathrm{om}}(\overline{\mathrm{t}})$ values are available for a much larger time-interval (say $-\infty<\overline{\mathrm{t}}<\infty$ or $-t_{1} \leq \bar{t} \leq t_{2}$ where $t_{1}>0$ and $t_{2}>0$ ). To begin with, impositions of superposed 
fluctuations in the initial conditions of the CFD problem are implemented for several values of $t_{1}$ over times $t \equiv \bar{t} \geq-t_{1}$. These computations establish that different solutions arising from initial conditions set at several different values of $t=-t_{1}$ all agree with one another at $t \geq 0$ provided the largest value of "- $t_{1}$ " (or smallest value of $t_{1}$ ) is no larger than "- $\varepsilon . "$ It is this computational solution's results (for which initial conditions were set at $t=-\varepsilon$ ) that are reported here for the initial condition independent zone of $t \geq 0$. This is because the interest lies only in the longer term solution behavior which is independent of the choice of initial conditions. Time-averaged variables (over time scales $\mathrm{T}$ - where time-duration $T>1 / f_{P}>1 / f_{F}$ is larger than characteristic times associated with the primary pulsation frequency and its relevant harmonics) and time-varying pulsatile flow variables are of interest in the frequency spectrum $f<f_{F}$. The interaction of frequencies present in the differential pressure boundary conditions with turbulent fluctuations (of all frequencies) is automatically taken care of by the turbulence model employed in the CFD solution. Accordingly if one eliminates frequencies $f>f_{F}$ by suitably filtering the experimentally obtained $\Delta \mathrm{p}_{\mathrm{om}}(\mathrm{t})$ signal employed in the inlet pressure boundary condition, no significant impact is expected on the CFD solution in the frequency spectrum $f<f_{F}$.

\subsubsection{Turbulence Model Independence Testing for Empirically Corrected Time-Varying Mass Flow Rates}

The incompressible mass flow rate values are expected to be quantitatively reasonable (with minimal dependence on the choice of turbulence model if the choice is within a well-tested class: such as the standard k- $\varepsilon$ model, RSM model, etc. described in [12-15]) and correct with regard to the qualitative nature of the predicted time variations of the flow rate $\dot{\mathrm{m}}_{\mathrm{CFD}-\mathrm{I} \mid \mathrm{om}}(\mathrm{t})$. This paper, however, proposes that even small model- 
dependent quantitative variations be removed and model independent values of $\dot{\mathrm{m}}_{\mathrm{CFD}-\mathrm{I} \mid \mathrm{om}}(\mathrm{t})$, denoted as $\dot{\mathrm{m}}_{\mathrm{Inc} \mid \mathrm{om}}(\mathrm{t})$, be obtained with the help of an empirical correction factor $\alpha$, as previously shown in Section 3.2.

In order to verify the turbulence-model independence feature of the empirical correction approach described in Section 3.2, it is noted that the CFD procedure (described in Section 3.1) used to obtain the mass flow rate $\dot{\mathrm{m}}_{\mathrm{CFD}-\mathrm{I} \mid \mathrm{OM} 1}(\mathrm{t})$ values in Fig. 9 employ the standard $k-\varepsilon$ turbulence model. This choice of turbulence model is termed Mod-1 and the associated mass flow rate $\dot{\mathrm{m}}_{\mathrm{CFD}-\mathrm{I} \mid \mathrm{OM} 1}(\mathrm{t})$ values and its empirically corrected value (through Eq. (1)) are respectively denoted as $\dot{\mathrm{m}}_{\mathrm{CFD}-\mathrm{I} \mid \mathrm{OM} 1-\operatorname{Mod} 1}(\mathrm{t})$ and $\dot{\mathrm{m}}_{\mathrm{Inc|OM1-Mod} 1}(\mathrm{t})$.

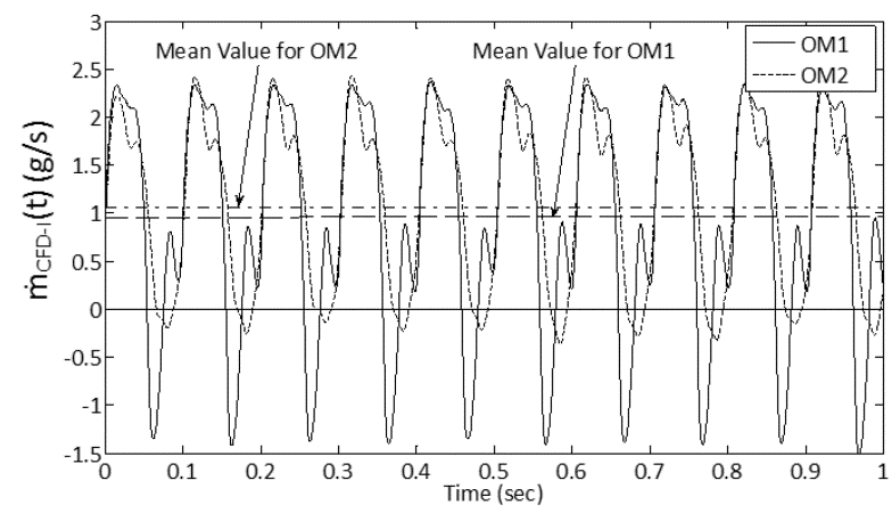

Figure 9: The representative solution associated with the pressure difference in Fig. 6

Similarly, for the same pressure-difference $\Delta \mathrm{p}_{\mathrm{OM} 1}(\mathrm{t})$ in Fig. 6, solution of Eq. (4) under the second turbulence-model choice, namely Reynolds Stress Model (RSM) of [14] termed Mod-2 leads to prediction of associated mass flow rate $\dot{\mathrm{m}}_{\mathrm{CFD}-\mathrm{I} \mid \mathrm{OM} 1-\mathrm{Mod} 2}(\mathrm{t})$ values. These $\dot{\mathrm{m}}_{\mathrm{CFD}-\mathrm{I} \mid \mathrm{OM} 1-\operatorname{Mod} 1}(\mathrm{t})$ and $\dot{\mathrm{m}}_{\mathrm{CFD}-\mathrm{I} \mid \mathrm{OM} 1-\operatorname{Mod} 2}(\mathrm{t})$ values are shown in Fig. 10. 


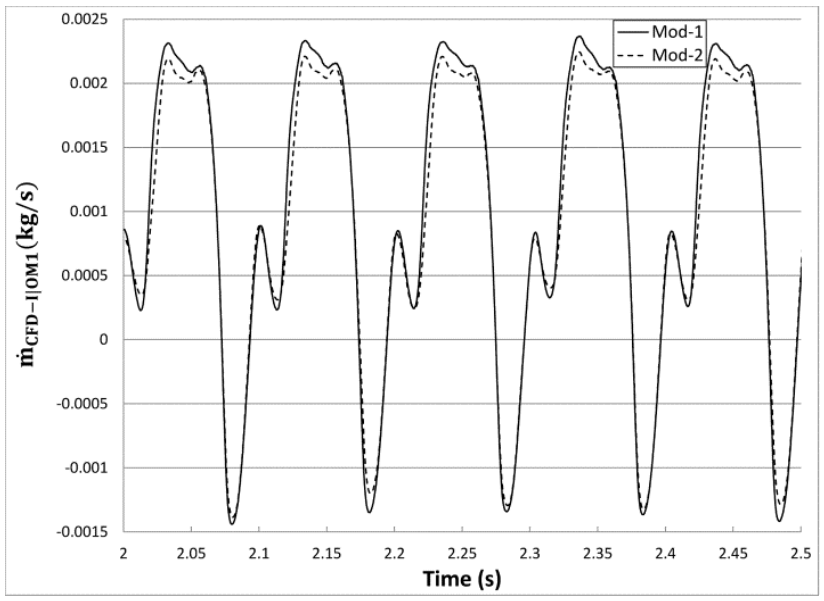

Figure 10: Plots of mass flow rate for two different turbulence models (Mod-1 and Mod-2) of run 3 in Table 4

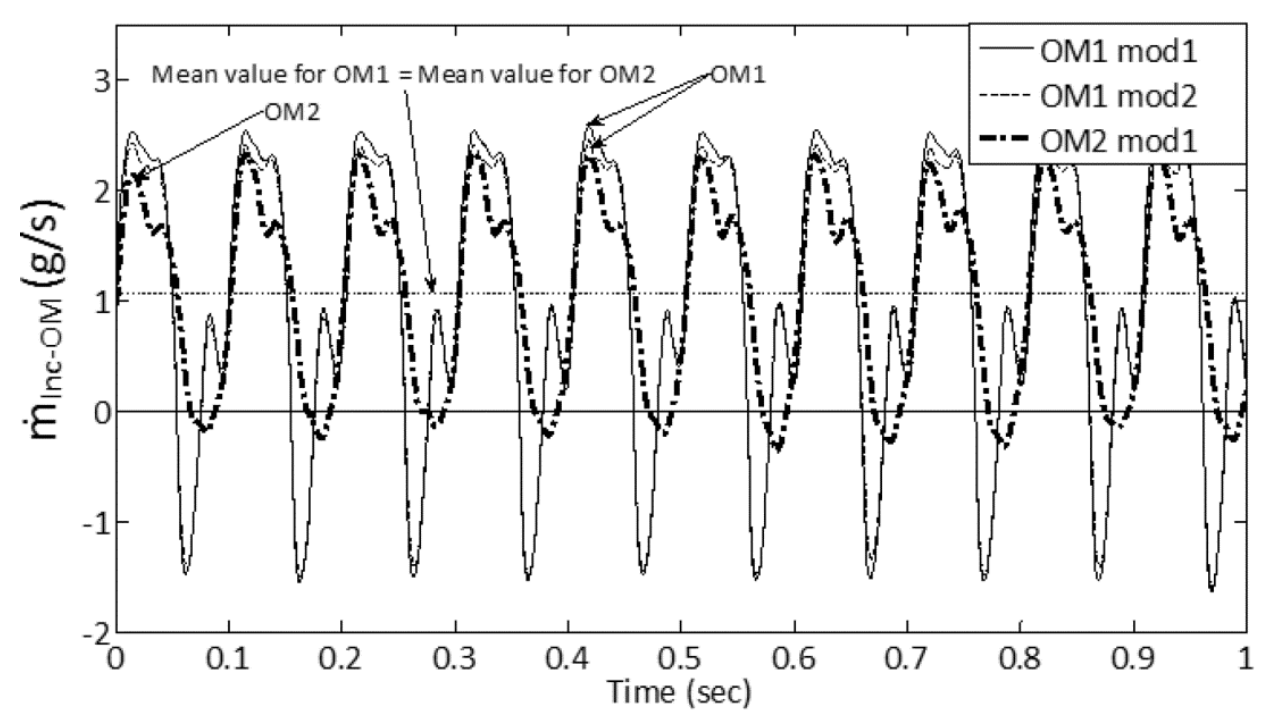

Figure 11: For the representative values of $\dot{\mathrm{m}}_{\mathrm{CFD}-\mathrm{I} \mid \mathrm{OM} 1}(\mathrm{t})$ and $\dot{\mathrm{m}}_{\mathrm{CFD}-\mathrm{I} \mid \mathrm{OM} 2}(\mathrm{t})$ in Fig. 9 , the Figure above shows the respective empirically corrected values $\dot{\mathrm{m}}_{\operatorname{Inc|0M1}}(\mathrm{t})=$ $\alpha \cdot \dot{\mathbf{m}}_{\mathrm{CFD}-\mathrm{I} \mid \mathrm{OM} 1}(\mathrm{t})$ and $\dot{\mathrm{m}}_{\mathrm{InC} \mid \mathrm{OM} 2}(\mathrm{t})=\alpha \cdot \dot{\mathbf{m}}_{\mathrm{CFD}-\mathrm{I} \mid \mathrm{OM} 2}(\mathrm{t})$ for turbulence model Mod 1. In addition, the figure also shows $\dot{m}_{\text {Inc|0M1 }}(t)$ for turbulence model Mod 2.

The graphical representation of these two mass flow rates in Figure 11 shows the empirically corrected values of $\dot{\mathrm{m}}_{\mathrm{CFD}-\mathrm{I} \mid \mathrm{OM} 1-\operatorname{Mod} 1}(\mathrm{t}), \dot{\mathrm{m}}_{\mathrm{CFD}-\mathrm{I} \mid \mathrm{OM} 1-\operatorname{Mod} 2}(\mathrm{t})$, and 


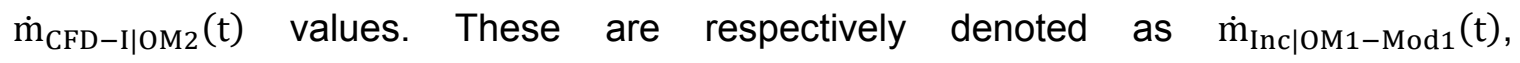
$\dot{\mathrm{m}}_{\mathrm{Inc} \mid \mathrm{OM} 1-\operatorname{Mod} 2}(\mathrm{t})$, and $\dot{\mathrm{m}}_{\mathrm{Inc} \mid \mathrm{OM} 2-\operatorname{Mod} 1}(\mathrm{t})$ in Fig. 11 and it is clear that indeed $\dot{\mathrm{m}}_{\mathrm{Inc|OM} 1-\mathrm{Mod} 1}(\mathrm{t})$ and $\dot{\mathrm{m}}_{\mathrm{Inc} \mid \mathrm{OM} 1-\mathrm{Mod} 2}(\mathrm{t})$ values are quite close to one another and thus independent (within errors that exist in obtaining $\alpha$ ) of the choice of turbulence models.

Unless otherwise stated, it should be assumed that all other incompressible CFD solutions employ the standard $k-\varepsilon$ turbulence model (i.e. Mod-1). This means that $\dot{\mathrm{m}}_{\mathrm{CFD}-\mathrm{I} \mid \mathrm{OM} 1}(\mathrm{t})$ is the same as $\dot{\mathrm{m}}_{\mathrm{CFD}-\mathrm{I} \mid \mathrm{OM} 1-\operatorname{Mod} 1}(\mathrm{t})$.

\subsection{Transient Compressibility Effects}

(Common between this thesis and [1])

Under low instantaneous or time-averaged Mach number conditions in a duct, it is well known (see [14]) that the local gas density $\rho$ as a function of position $\mathbf{x}$ (see $\overrightarrow{\mathbf{x}}$ in Fig. 8) and time $t$ is adequately represented by a reference constant density $\rho_{0}$ through:

$$
\rho(\mathbf{x}, \mathrm{t})=\rho_{0}+\rho^{\prime}(\mathbf{x}, \mathrm{t})=\rho_{0}\left[1+\frac{\rho^{\prime}(\mathbf{x}, \mathrm{t})}{\rho_{0}}\right] \cong \rho_{0}
$$

because $\left|\frac{\rho^{\prime}(\mathrm{x}, \mathrm{t})}{\rho_{0}}\right| \ll 1$. Over the unsteady time-scale of interest $\left(\Delta \mathrm{t}_{\mathrm{c}} \sim 1 / \mathrm{f}_{\mathrm{P}}-\right.$ where $\mathrm{f}_{\mathrm{P}}$ is the predominant externally imposed frequency), the transient compressibility effects may still be significant because of the importance of the $\partial \rho / \partial$ t term. A full compressible model solution approach can account for the transient compressibility effects and is briefly discussed in section 3.4.2 while being further expanded on in [1].

In Narain et al. [2], it was proposed that an approximate modeling approach that is based on the assumption that the incompressible model-based mass flow rate obtained in the earlier section can be corrected because the acoustics-induced $\partial \rho / \partial \mathrm{t}$ term is primarily due to the time-varying pressure variations $p(\mathbf{x}, t)$ for which a very good 
estimate is available through $\mathrm{p}(\mathbf{x}, \mathrm{t}) \equiv \mathrm{p}_{\mathrm{CFD}}(\mathbf{x}, \mathrm{t})+\left\{\mathrm{p}_{\mathrm{u}}(\mathrm{t})-\Delta \mathrm{p}_{\mathrm{om}}(\mathrm{t})\right\}$ which describes the physical pressure field and the incompressible $\mathrm{p}_{\mathrm{CFD}}(\mathbf{x}, \mathrm{t})$ values that are part of the solution obtained by the approach outlined in [2]. Therefore once this $\partial \rho / \partial \mathrm{t}$ term effect on the overall mass balance (or continuity equation) is assessed, one can correct the incompressible model mass flow rate values obtained in the earlier section.

To consider the effect of the $\partial \rho / \partial \mathrm{t}$ term on the overall mass balance (or continuity equation), note that the mass balance equation for the orifice meter (written for the fixed interior volume $V_{0}$ enclosed by the orifice meter between cross-sections $U$ and D in Fig. 1) is:

$$
\dot{\mathrm{m}}_{\text {stored }}(\mathrm{t}) \equiv \int_{\mathrm{V}_{0}} \frac{\partial \rho}{\partial \mathrm{t}} \cdot \mathrm{dvol}=\dot{\mathrm{m}}_{\mathrm{U}}(\mathrm{t})-\dot{\mathrm{m}}_{\mathrm{D}}(\mathrm{t})
$$

where $\dot{\mathrm{m}}_{\mathrm{U}}(\mathrm{t}) \equiv \int_{\mathrm{A}_{0}} \rho_{\mathrm{U}}(\mathbf{v} \cdot \mathbf{i}) \cdot d a \cong \rho_{0} \cdot \mathrm{Q}_{\mathrm{U}}(\mathrm{t})$ and $\dot{\mathrm{m}}_{\mathrm{D}}(\mathrm{t}) \equiv \int_{\mathrm{A}_{0}} \rho_{\mathrm{D}}(-\mathbf{v} \cdot \mathbf{i}) \cdot d a \cong \rho_{0} \cdot \mathrm{Q}_{\mathrm{D}}(\mathrm{t})$ are time-varying values of cross-sectional mass flow rates (with $Q_{U}(t)$ and $Q_{D}(t)$ denoting cross-sectional volume flow rates) associated with locations $U$ and $D$ in Fig. 8. The simplifying expressions for $\dot{\mathrm{m}}_{\mathrm{U}}(\mathrm{t}) \cong \rho_{0} \cdot \mathrm{Q}_{\mathrm{U}}(\mathrm{t})$ and $\dot{\mathrm{m}}_{\mathrm{D}}(\mathrm{t}) \cong \rho_{0} \cdot \mathrm{Q}_{\mathrm{D}}(\mathrm{t})$ in Eq. (6) are not needed but they are valid nevertheless because of the valid approximation in Eq. (5). Note that, in Fig. 8, the cross-section at $D$ is at a distance $x=I_{o m}$ downstream of the cross-section at $U$ and that the cross-sectional areas at both these locations are the same and denoted as $A_{0}$. Also, observe that in Fig. 1, the scalar distance $x$ associated with a point $\mathrm{P}$ is the axial projection of the vector $\mathbf{x}$ which locates it. Under low Mach number pulsatile flow conditions, flows will exhibit transient compressibility effects if the left side of Eq. (6) is significant (over $t^{*} \leq t \leq t^{*}+\Delta t_{c}$ for any $t^{*}$ and $\Delta t_{c} \sim 1 / f_{P}$ ) with respect to one of the cross-sectional mass flow rates on the right side of Eq. (6). Let the reference constant density $\rho_{0}$ be chosen to be one which is thermodynamically related to the steady time-averaged (as well as cross-sectionally averaged) values of pressure 
$\mathrm{p}_{\mathrm{U}}(\mathrm{t})$, denoted as $\overline{\mathrm{p}}_{\mathrm{U}} \equiv \mathrm{p}_{0}$, and temperature $\mathrm{T}_{\mathrm{U}}(\mathrm{t})$, denoted as $\overline{\mathrm{T}}_{\mathrm{U}} \equiv \mathrm{T}_{0}$. These mean values of pressure and temperature are associated with the cross-section location $U$ in Fig. 8. That is (see [14]):

$$
\rho_{0}=\hat{\rho}_{0}\left(\mathrm{p}_{0}, \mathrm{~T}_{0}\right)=\tilde{\rho}_{0}\left(\mathrm{p}_{0}, \mathrm{~s}_{0}\right)
$$

where $\hat{\rho}_{0}$ and $\tilde{\rho}_{0}$ are equilibrium thermodynamic equations of state and $\mathrm{s}_{0}=\mathrm{s}_{0}\left(\mathrm{p}_{0}, \mathrm{~T}_{0}\right)$ is the specific entropy associated with gas phase pressure $p_{0}$ and temperature $T_{0}$. The difference between physical pressure $p$ and reference pressure $p_{0}$ is termed:

$$
\mathrm{p}_{\mathrm{off}}^{\prime}(\mathbf{x}, \mathrm{t}) \equiv \mathrm{p}(\mathbf{x}, \mathrm{t})-\mathrm{p}_{0}
$$

and it is noted that, despite mechanically non-equilibrium flow conditions at the macroscale, the flow conditions typically satisfy $\left|\frac{\rho^{\prime}(\mathrm{x}, \mathrm{t})}{\rho_{0}}\right| \ll 1$ and $\left|\frac{\mathrm{p}_{\mathrm{off}}^{\prime}(\mathrm{x}, \mathrm{t})}{\mathrm{p}_{0}}\right| \ll 1$ at all times. Therefore the principle of local equilibrium thermodynamics continues to hold at the fluid element level. That is, at any point $\mathbf{x}$ and time $\mathrm{t}$, the local density $\rho(\mathbf{x}, \mathrm{t})=\rho_{0}+\rho^{\prime}(\mathbf{x}, \mathrm{t})$ continues to relate to local absolute pressure $\mathrm{p}(\mathbf{x}, \mathrm{t}) \equiv \mathrm{p}_{0}+\mathrm{p}_{\mathrm{off}}^{\prime}(\mathbf{x}, \mathrm{t})$ through the thermodynamic relationship in Eq. (7). Also, approximate constancy of the local entropy $s(\mathbf{x}, t) \equiv s_{0}$ holds. This is a well-known [14] approximation for the nearly adiabatic conditions in the interior gas flow regions arising from low gas-phase thermal conductivity and insignificant heat flow rate through the thermally insulated walls of the orifice meter. Therefore, the following thermodynamic relation holds:

$$
\rho(\mathbf{x}, \mathrm{t})=\rho_{0}+\rho^{\prime}(\mathbf{x}, \mathrm{t})=\tilde{\rho}_{0}\left(\mathrm{p}_{0}+\mathrm{p}_{\text {off }}^{\prime}(\mathbf{x}, \mathrm{t}), \mathrm{s}_{0}\right) .
$$

Because $\rho^{\prime}$ is small with respect to $\rho_{0}$ and $\mathrm{p}_{\text {off }}^{\prime}$ is small with respect to $\mathrm{p}_{0}$, one term Taylor approximation of Eq. (9) implies:

$$
\rho^{\prime}(\mathbf{x}, \mathrm{t}) \cong\left\{\partial \tilde{\rho}_{0}\left(\mathrm{p}_{0}, \mathrm{~s}_{0}\right) / \partial \mathrm{p}_{0}\right\} \cdot \mathrm{p}_{\mathrm{off}}^{\prime}(\mathbf{x}, \mathrm{t}) \equiv\left(\frac{1}{\mathrm{c}_{0}^{2}}\right) \mathrm{p}_{\mathrm{off}}^{\prime}(\mathbf{x}, \mathrm{t})
$$

where $\mathrm{c}_{0} \equiv \sqrt{\partial \mathrm{p}_{0}\left(\rho_{0}, \mathrm{~s}_{0}\right) / \partial \rho_{0}}$ is the speed of sound [14] at the reference thermodynamic condition. For FC-72 vapor and pulsatile flow conditions of interest in Table 4, it is known 
that $\mathrm{c}_{0}$ is in the range of $92.7 \leq \mathrm{c}_{0} \leq 93.2 \mathrm{~m} / \mathrm{s}$ from a superheated properties table for FC-72 (provided by the fluid's manufacturer 3M Corp.).

Taking the time derivative of Eq. (10), one obtains:

$$
\frac{\partial \rho^{\prime}}{\partial \mathrm{t}}(\mathbf{x}, \mathrm{t})=\left(\frac{1}{\mathrm{c}_{0}^{2}}\right) \cdot \frac{\partial \mathrm{p}_{\mathrm{off}}^{\prime}}{\partial \mathrm{t}}(\mathbf{x}, \mathrm{t})
$$

Substituting the expression in Eq. (11) for the integrand on the left side of Eq. (6), one obtains:

$$
\dot{\mathrm{m}}_{\text {stored }}(\mathrm{t}) \equiv \int_{\mathrm{V}_{0}} \frac{\partial \rho}{\partial \mathrm{t}} \cdot \mathrm{dvol}=\frac{1}{\mathrm{c}_{0}^{2}} \cdot \frac{\mathrm{d}}{\mathrm{dt}}\{\mathrm{I}(\mathrm{t})\}
$$

where

$$
\mathrm{I}(\mathrm{t}) \equiv \int_{\mathrm{V}_{0}} \mathrm{p}_{\mathrm{off}}^{\prime}(\mathrm{x}, \mathrm{t}) \cdot \mathrm{dvol}
$$

Introducing the notation $\mathrm{p}_{U}(\mathrm{t}) \equiv \overline{\mathrm{p}}_{\mathrm{U}}+\mathrm{p}_{\mathrm{U}}^{\prime}(\mathrm{t})$, and recalling $\mathrm{p}_{0} \equiv \overline{\mathrm{p}}_{\mathrm{U}}$ and $\mathrm{p}(\mathbf{x}, \mathrm{t})=\mathrm{p}_{\mathrm{CFD}}(\mathbf{x}, \mathrm{t})+$ $\left\{\mathrm{p}_{\mathrm{u}}(\mathrm{t})-\Delta \mathrm{p}_{\mathrm{om}}(\mathrm{t})\right\}$ along with Eq. (6), that $\mathrm{p}_{\mathrm{off}}^{\prime}(\mathbf{x}, \mathrm{t})=\mathrm{p}_{\mathrm{CFD}}(\mathbf{x}, \mathrm{t})+\left\{\mathrm{p}_{\mathrm{U}}^{\prime}(\mathrm{t})-\Delta \mathrm{p}_{\mathrm{om}}(\mathrm{t})\right\}$. Thus $\mathrm{p}_{\mathrm{off}}^{\prime}(\mathbf{x}, \mathrm{t})$ is known for each experimental run in Tables 4-5. It is also clear that the nondimensional values of $\mathrm{p}_{\text {off }}^{\prime}(\mathbf{x}, \mathrm{t})$, defined as "nd- $\mathrm{p}_{\mathrm{off}}^{\prime}(\mathbf{x}, \mathrm{t})$, , through the relation:

$$
n d-p_{\text {off }}^{\prime}(x, t) \equiv \frac{p_{U}^{\prime}(t)-p_{\text {off }}^{\prime}(x, t)}{\Delta p_{o m}(t)}=1-\frac{p_{C F D}(x, t)}{\Delta p_{o m}(t)}
$$

will make, for all experimental runs, nd- $p_{\text {off }}^{\prime}(\mathbf{x}, \mathrm{t})=0$ for $\mathbf{x}$ on the cross-section $U$ (i.e. $\mathbf{x}=$ 0 in Fig. 8) and nd- $p_{\text {off }}^{\prime}(x, t)=1$ for $\mathbf{x}$ on the cross-section $D$ (i.e. $x=I_{o m}$ in Fig. 8). This makes, as one considers different flows in different experimental runs of Tables 4-5, changes in $n d-p_{\text {off }}^{\prime}(x, t)$ values less significant than the changes in $p_{\text {off }}^{\prime}(x, t)$ values. If care is taken to avoid zeroes of $\Delta \mathrm{p}_{\mathrm{om}}(\mathrm{t})$ while evaluating nd- $\mathrm{p}_{\mathrm{off}}^{\prime}(\mathrm{x}, \mathrm{t})$ in Eq. (14), it is preferable to replace the use of $p_{\text {off }}^{\prime}(x, t)$ by nd- $p_{\text {off }}^{\prime}(x, t)$ for evaluation of the integral I(t) in Eq. (13). Introducing the non-dimensional integral:

$$
\mathrm{NI}(\mathrm{t}) \equiv\left(\frac{1}{\mathrm{~V}_{0}}\right) \cdot \int_{\mathrm{V}_{0}} \mathrm{nd}-\mathrm{p}_{\mathrm{off}}^{\prime}(\mathbf{x}, \mathrm{t}) \cdot \mathrm{dvol}
$$


and using it to rewrite the integral in Eq. (13), one obtains:

$$
\mathrm{I}(\mathrm{t}) \equiv\left\{\mathrm{p}_{\mathrm{U}}^{\prime}(\mathrm{t})-\Delta \mathrm{p}_{\mathrm{om}}(\mathrm{t}) \cdot \mathrm{NI}(\mathrm{t})\right\} \cdot \mathrm{V}_{0}
$$

A sample plot of the computationally obtained $\mathrm{NI}(\mathrm{t})$ values for the representative run 3 in Tables $4-5$ is shown in [1]. It is found that for all cases in Tables 4-5, $\mathrm{NI}(\mathrm{t}) \cong \overline{\mathrm{NI}} \cong 0.5$ - with small case-dependent variations in $\overline{\mathrm{NI}}$ values (typically between 0.48 to 0.52 ) among different cases. This is because of a rather universal nature of the cross-sectional average values of $n d-p_{\text {off }}^{\prime}(x, t)$ profile. Note that 0.5 is the value associated with the right hand side of Eq. (15) if the assumption of linear variation, between $x=0$ and $x=I_{o m}$ in Fig. 8 , is assumed for the cross-sectional average values of $n d-p_{o f f}^{\prime}-a v(x, t)$.

Using Eq. (16) in Eq. (12), one obtains the following useful expression for $\dot{\mathrm{m}}_{\text {stored }}(\mathrm{t})$ in Eqs. (6) and (12):

$$
\dot{\mathrm{m}}_{\text {stored }}(\mathrm{t}) \equiv \dot{\mathrm{m}}_{\text {stored-AP }}(\mathrm{t})+\dot{\mathrm{m}}_{\text {stored-DP }}(\mathrm{t}) \text {, }
$$

where

$$
\dot{\mathrm{m}}_{\text {stored-AP }}(\mathrm{t}) \equiv \frac{\mathrm{d}}{\mathrm{dt}}\left\{\mathrm{p}_{\mathrm{U}}^{\prime}(\mathrm{t})\right\} \cdot \frac{\mathrm{V}_{0}}{\mathrm{c}_{0}^{2}}
$$

and

$$
\dot{\mathrm{m}}_{\text {stored-DP }}(\mathrm{t}) \equiv-\frac{\mathrm{d}}{\mathrm{dt}}\left\{\Delta \mathrm{p}_{\mathrm{om}}(\mathrm{t}) \cdot \mathrm{NI}(\mathrm{t})\right\} \cdot \frac{\mathrm{v}_{0}}{\mathrm{c}_{0}^{2}}
$$

The $\dot{\mathrm{m}}_{\text {stored-AP }}$ contribution to $\dot{\mathrm{m}}_{\text {stored }}$ in Eq. (17) represents the acoustic effects associated with uniform absolute pressure fluctuations $\mathrm{p}_{U}^{\prime}(\mathrm{t}) \equiv \mathrm{p}_{\mathrm{U}}(\mathrm{t})-\overline{\mathrm{p}}_{\mathrm{U}}$ over $0 \leq \mathrm{x} \leq$ $\mathrm{I}_{\mathrm{om}}$ in Fig. 8. This contribution is easily computed from the $\dot{\mathrm{m}}_{\text {stored-AP }}$ expression in Eq. (18). Similarly the $\dot{\mathrm{m}}_{\text {stored-DP }}$ contribution to $\dot{\mathrm{m}}_{\text {stored }}$ in Eq. (17) is given by the right side of Eq. (19). This expression represents the acoustic effects associated with the nonuniform values of absolute pressure variations represented by the pressure-difference 
" $p(x, t)-p_{U}(t)$ " for all $\mathbf{x}$ within the orifice-meter (i.e. over $\left.0 \leq x \leq I_{o m}\right)$. These effects also scale with volume $\mathrm{V}_{0}$ in Eqs. (16-19), and by extension Eq. (12).

Table 4: Orifice-meter OM1 and orifice-meter OM2 Input Data

\begin{tabular}{|c|c|c|c|c|c|c|c|c|c|c|c|}
\hline & & & & \multicolumn{4}{|c|}{ OM1 Input Data } & \multicolumn{4}{c|}{ OM2 Input Data } \\
\hline & $\mathrm{f}_{\mathrm{p}}$ & $\overline{\dot{m}}_{F C-1}$ & $\overline{\dot{m}}_{F C-2}$ & $\bar{p}_{L}$ & $a_{p^{\prime}-L}$ & $\overline{\Delta p}_{O M 1}$ & $a_{\triangle p-O M 1}$ & $\bar{p}_{M}$ & $a_{p^{\prime}-M}$ & $\overline{\Delta p}_{O M 2}$ & $a_{\triangle p-O M 2}$ \\
\hline $\begin{array}{c}\text { Run } \\
H\end{array}$ & $\mathrm{~Hz}$ & $\mathrm{~g} / \mathrm{s}$ & $\mathrm{g} / \mathrm{s}$ & $\mathrm{kPa}$ & $\mathrm{Pa}$ & $\mathrm{Pa}$ & $\mathrm{Pa}$ & $\mathrm{kPa}$ & $\mathrm{Pa}$ & $\mathrm{Pa}$ & $\mathrm{Pa}$ \\
\hline 1 & 3.8 & 1.0519 & 1.0270 & 142.0 & 1806 & 263 & 364.1 & 142.2 & 1625 & 78 & 100.5 \\
\hline 2 & 3.8 & 1.0514 & 1.0271 & 141.9 & 2769 & 364 & 668.7 & 142.0 & 2675 & 100 & 159.5 \\
\hline 3 & 10 & 1.0501 & 1.0270 & 142.3 & 716 & 235 & 430.6 & 142.4 & 549 & 75 & 211.9 \\
\hline 4 & 9.8 & 1.0091 & 1.0283 & 143.4 & 1152 & 360 & 749.8 & 143.4 & 536 & 109 & 329.0 \\
\hline 5 & 3.8 & 0.4637 & 0.4070 & 147.8 & 1305 & 108 & 167.8 & 148.1 & 1333 & 23 & 48.9 \\
\hline 6 & 3.8 & 0.4849 & 0.4075 & 146.1 & 1287 & 75 & 144.0 & 146.4 & 1323 & 20 & 45.5 \\
\hline 7 & 10 & 0.4869 & 0.4112 & 147.7 & 909 & 159 & 493.2 & 148.0 & 810 & 56 & 241.3 \\
\hline 8 & 10 & 0.5174 & 0.4125 & 145.5 & 1395 & 223 & 897.2 & 145.7 & 1113 & 72 & 360.0 \\
\hline
\end{tabular}

Table 5: Orifice-meter OM1 and orifice-meter OM2 Output Data

\begin{tabular}{|c|c|c|c|c|c|c|c|c|}
\hline & & \multicolumn{3}{|c|}{ OM1 Output Data } & \multicolumn{3}{|c|}{ OM2 Output Data } & \\
\hline & $f_{p}$ & $a_{\dot{m}-I n c}$ & $\begin{array}{l}a_{\dot{m}-M} \\
=a_{m-L}\end{array}$ & $\begin{array}{l}\text { Difference from } \\
\text { Incompressible }\end{array}$ & $a_{\dot{m}-I n c}$ & $a_{\dot{m}-O}=a_{m-N}$ & $\begin{array}{c}\text { Difference } \\
\text { from } \\
\text { Incompressible }\end{array}$ & \\
\hline $\begin{array}{c}\text { Run } \\
\#\end{array}$ & $\mathrm{~Hz}$ & $\mathrm{~g} / \mathrm{s}$ & $\mathrm{g} / \mathrm{s}$ & $\%$ & $\mathrm{~g} / \mathrm{s}$ & $\mathrm{g} / \mathrm{s}$ & $\%$ & $\%$ \\
\hline 1 & 3.8 & 0.8804 & 0.9526 & 8.20 & 0.6785 & 0.8427 & 24.20 & -11.54 \\
\hline 2 & 3.8 & 1.6152 & 1.7238 & 6.72 & 1.2231 & 1.3371 & 9.32 & -22.43 \\
\hline 3 & 10 & 1.7322 & 1.8062 & 4.27 & 1.1961 & 1.2856 & 7.48 & -28.82 \\
\hline 4 & 9.8 & 3.0877 & 3.2076 & 3.88 & 2.7399 & 2.8206 & 2.95 & -12.07 \\
\hline 5 & 3.8 & 0.6458 & 0.6948 & 7.59 & 0.4997 & 0.5767 & 15.41 & -17.00 \\
\hline 6 & 3.8 & 0.5459 & 0.5988 & 9.69 & 0.4457 & 0.5283 & 18.53 & -11.77 \\
\hline 7 & 10 & 1.7881 & 1.8853 & 5.44 & 1.2325 & 1.4245 & 15.58 & -24.44 \\
\hline 8 & 10 & 3.0745 & 3.2217 & 4.79 & 2.7428 & 2.8947 & 5.54 & -10.15 \\
\hline
\end{tabular}

\subsubsection{Cross-section Specific Mass Flow Rates Obtained from Transient Compressibility} Corrections on the Incompressible Model Mass Flow Rate

It should be noted that the compressibility estimate in Eq. (6) is not sufficient to yield the specific cross-sectional mass flow rates $\dot{\mathrm{m}}_{U}(\mathrm{t})$ and $\dot{\mathrm{m}}_{\mathrm{D}}(\mathrm{t})$. To obtain cross- 
section specific mass flow rates in a gas line, one needs to obtain the actual mass flow for at least one cross-section in a gas line.

In general, one cannot obtain either $\dot{\mathrm{m}}_{\mathrm{U}}(\mathrm{t})$ or $\dot{\mathrm{m}}_{\mathrm{D}}(\mathrm{t})$ by the measurements in Fig. 8 and the incompressible mass flow rate simulation approach described earlier. However cross-section specific values can be obtained by the compressible solution approach described in Section 3.4.2. However, the devices in Fig. 2, Fig. 3, and Fig. 8 are symmetric with respect to the central cross-section in the flow direction. For these cases, an approach which uses the incompressible model's simulation results to obtain the estimates for the actual time-varying mass flow rates at the cross-sections where orificemeter pressure taps are located (e.g. $U$ and D in Fig. 8) was presented in [2]. These mass flow rate values at $U$ and $D$ in Fig. 8 should account for acoustic wave effects' contributions to $\dot{\mathrm{m}}_{\text {stored }}$ and are respectively denoted as $\dot{\mathrm{m}}_{\mathrm{U}}(\mathrm{t})$ and $\dot{\mathrm{m}}_{\mathrm{D}}(\mathrm{t})$. To obtain them, the value of $\dot{\mathrm{m}}_{\mathrm{Inc|om}}(\mathrm{t})$ obtained in Section 3.2 is used to model the following mass flow rate correction terms:

$$
\Delta \dot{\mathrm{m}}_{\mathrm{U}}(\mathrm{t}) \equiv \dot{\mathrm{m}}_{\mathrm{U}}(\mathrm{t})-\dot{\mathrm{m}}_{\text {Inc|om }}(\mathrm{t})
$$

and

$$
\Delta \dot{\mathrm{m}}_{\mathrm{D}}(\mathrm{t}) \equiv \dot{\mathrm{m}}_{\mathrm{D}}(\mathrm{t})-\dot{\mathrm{m}}_{\text {Inc|om }}(\mathrm{t})
$$

This modeling approach consists of considering $\dot{\mathrm{m}}_{\text {stored-AP }}$ and $\dot{\mathrm{m}}_{\text {stored-DP }}$ contributions in Eq. (17) to be due to a superposition of two separate physical mechanisms by which acoustic effects contribute to the $\Delta \dot{\mathrm{m}}_{\mathrm{U}}(\mathrm{t})$ and $\Delta \dot{\mathrm{m}}_{\mathrm{D}}(\mathrm{t})$ terms in Eq. (20).

The first physical effect is associated with homogeneous pressure field fluctuations $\mathrm{p}_{\mathrm{U}}^{\prime}(\mathrm{t})$ in the symmetric orifice-meter. This causes a homogeneous density change in a way that, when $\dot{\mathrm{m}}_{\text {stored-AP }}>0$ in Eq. (18), the density increases and sets up two equal mass flow rates $\left(\dot{\mathrm{m}}_{\text {stored-AP}} / 2\right)$ that are drawn in through the two crosssections $U$ and $D$ of the orifice-meter in Fig. 8. The associated mass flow rates' 
contributions to $\Delta \dot{\mathrm{m}}_{\mathrm{U}}(\mathrm{t})$ and $\Delta \dot{\mathrm{m}}_{\mathrm{D}}(\mathrm{t})$ are respectively termed $\Delta \dot{\mathrm{m}}_{\mathrm{U}-\mathrm{AP}}(\mathrm{t})$ and $\Delta \dot{\mathrm{m}}_{\mathrm{D}-\mathrm{AP}}(\mathrm{t})$. Noting the sign convention for $\dot{\mathrm{m}}_{\mathrm{U}}(\mathrm{t})$ and $\dot{\mathrm{m}}_{\mathrm{D}}(\mathrm{t})$ are such that each are considered positive when the flow is from $U$ to $D$, the above description implies the following expressions:

$$
\Delta \dot{\mathrm{m}}_{\mathrm{U}-\mathrm{AP}}(\mathrm{t}) \equiv \dot{\mathrm{m}}_{\text {stored-AP }} / 2
$$

and

$$
\Delta \dot{\mathrm{m}}_{\mathrm{D}-\mathrm{AP}}(\mathrm{t}) \equiv-\dot{\mathrm{m}}_{\text {stored-AP }} / 2
$$

The second physical effect is associated with the fact that absolute pressure fluctuations vary with distance $\mathrm{x}$ (see Fig. 8). Mass flow rate at any interior location $\mathrm{x}$ can account for these effects by considering the stored mass contributions and a modification of Eq. (6) for a mass balance between $x=0$ and an arbitrary $x \leq I_{o m}$ in Fig. 8. Since absolute pressure fluctuation effects associated with $p_{U}(t)$ are already accounted for, these effects are associated with time varying components of pressuredifference fluctuations $\left\{\mathrm{p}(\mathrm{x}, \mathrm{t})-\mathrm{p}_{\mathrm{U}}(\mathrm{t})\right\} \equiv-\Delta \mathrm{p}_{\mathrm{om}}(\mathrm{t}) \cdot \mathrm{nd}-\mathrm{p}_{\text {off }}^{\prime}(\mathrm{x}, \mathrm{t})$. The contributions of these pressure-difference fluctuations to stored mass flow rate values between $x=0$ and an arbitrary $\mathrm{x} \leq \mathrm{I}_{\mathrm{om}}$ in Fig. 8 is termed $\Delta \dot{\mathrm{m}}_{\mathrm{x}-\mathrm{DP}}(\mathrm{t})$. The $\Delta \dot{\mathrm{m}}_{\mathrm{x}-\mathrm{DP}}(\mathrm{t})$ for $\mathrm{x}=0$ is termed $\Delta \dot{\mathrm{m}}_{\mathrm{U}-\mathrm{DP}}(\mathrm{t})$ and for $\mathrm{x}=\mathrm{I}_{\mathrm{om}}$ is termed $\Delta \dot{\mathrm{m}}_{\mathrm{D}-\mathrm{DP}}(\mathrm{t})$. Since the volume between $\mathrm{x}=0$ and an arbitrary $\mathrm{x} \leq \mathrm{I}_{\mathrm{om}}$ in Fig. 8 tends to zero as $\mathrm{x}$ tends to zero, the contribution to $\Delta \dot{\mathrm{m}}_{\mathrm{U}-\mathrm{DP}}(\mathrm{t})$ associated with these pressure-difference fluctuations is zero. Similarly the contribution of these fluctuations to $\Delta \dot{\mathrm{m}}_{\mathrm{D}-\mathrm{DP}}(\mathrm{t})$ between $U$ and $\mathrm{D}$ in Fig. 8 is the entire $\dot{\mathrm{m}}_{\text {stored-DP }}(\mathrm{t})$ term in Eq. (23). Therefore the second acoustic effect is modeled through the following expressions:

$$
\Delta \dot{\mathrm{m}}_{\mathrm{U}-\mathrm{DP}}(\mathrm{t}) \equiv 0
$$


and

$$
\Delta \dot{\mathrm{m}}_{\mathrm{D}-\mathrm{DP}}(\mathrm{t}) \equiv-\dot{\mathrm{m}}_{\text {stored-DP }}(\mathrm{t})
$$

The hypothesis that concurrent superposition of the two above described acoustic effects contributes to the $\Delta \dot{\mathrm{m}}_{\mathrm{U}}(\mathrm{t})$ and $\Delta \dot{\mathrm{m}}_{\mathrm{D}}(\mathrm{t})$ terms in Eq. (20) yields the compressibility corrected mass flow rates as:

$$
\dot{\mathrm{m}}_{\mathrm{U}}(\mathrm{t}) \equiv \dot{\mathrm{m}}_{\text {Inc|om }}(\mathrm{t})+\Delta \dot{\mathrm{m}}_{\mathrm{U}}(\mathrm{t})
$$

where $\Delta \dot{\mathrm{m}}_{\mathrm{U}}(\mathrm{t}) \equiv\left\{\Delta \dot{\mathrm{m}}_{\mathrm{U}-\mathrm{AP}}(\mathrm{t})+\Delta \dot{\mathrm{m}}_{\mathrm{U}-\mathrm{DP}}(\mathrm{t})\right\}=\frac{1}{2} \cdot \frac{\mathrm{d}}{\mathrm{dt}}\left\{\mathrm{p}_{\mathrm{U}}^{\prime}(\mathrm{t})\right\} \cdot \frac{\mathrm{v}_{0}}{\mathrm{c}_{0}^{2}}$ and

$$
\dot{\mathrm{m}}_{\mathrm{D}}(\mathrm{t}) \equiv \dot{\mathrm{m}}_{\text {Inc|om }}(\mathrm{t})+\Delta \dot{\mathrm{m}}_{\mathrm{D}}(\mathrm{t})
$$

where $\Delta \dot{\mathrm{m}}_{\mathrm{D}}(\mathrm{t}) \equiv\left\{\Delta \dot{\mathrm{m}}_{\mathrm{D}-\mathrm{AP}}(\mathrm{t})+\Delta \dot{\mathrm{m}}_{\mathrm{D}-\mathrm{DP}}(\mathrm{t})\right\}=-\frac{1}{2} \cdot \frac{\mathrm{d}}{\mathrm{dt}}\left\{\mathrm{p}_{\mathrm{U}}^{\prime}(\mathrm{t})\right\} \cdot \frac{\mathrm{V}_{0}}{\mathrm{c}_{0}^{2}}+\frac{\mathrm{d}}{\mathrm{dt}}\left\{\Delta \mathrm{p}_{\mathrm{om}}(\mathrm{t}) \cdot \mathrm{NI}(\mathrm{t})\right\} \cdot \frac{\mathrm{V}_{0}}{\mathrm{c}_{0}^{2}}$.

The right-hand sides of Eqs. (23)-(24) are easily computed along with $\dot{\mathrm{m}}_{\text {Inc|om }}(\mathrm{t})$ values obtained in Section 3.2. With $U$ and $D$ in Fig. 8 corresponding to cross-sections $L$ and $\mathrm{M}$ for $\mathrm{OM} 1$ in Fig. 2, the above procedure yields cross-section specific mass flow rates $\dot{\mathrm{m}}_{\mathrm{L}}(\mathrm{t})$ and $\dot{\mathrm{m}}_{M}(\mathrm{t})$. For the representative run 4 in Tables 4-5, the absolute pressure fluctuations $\mathrm{p}_{\mathrm{L}}^{\prime}(\mathrm{t}) \equiv \mathrm{p}_{\mathrm{L}}(\mathrm{t})-\overline{\mathrm{p}}_{\mathrm{L}}$ and $\mathrm{p}_{\mathrm{M}}^{\prime}(\mathrm{t}) \equiv \mathrm{p}_{\mathrm{L}}^{\prime}(\mathrm{t})-\Delta \mathrm{p}_{\mathrm{OM} 1}(\mathrm{t})$ are as in Fig. 12 and their FFT are shown in Fig. 13. For representative run 6 in Tables 4-5, the time-varying values of $\dot{\mathrm{m}}_{\mathrm{L}}(\mathrm{t})$ and $\dot{\mathrm{m}}_{\mathrm{M}}(\mathrm{t})$ shown in Fig. 14 are found to be reasonably close to one another (within $10 \%$ ) and to $\dot{\mathrm{m}}_{\mathrm{Inc|OM} 1}(\mathrm{t})$. For all the runs in Tables $4-5, \dot{\mathrm{m}}_{\mathrm{L}}(\mathrm{t})$ and $\dot{\mathrm{m}}_{\mathrm{M}}(\mathrm{t})$ are close to one another and the reasons are discussed in Section 3.4.3. 


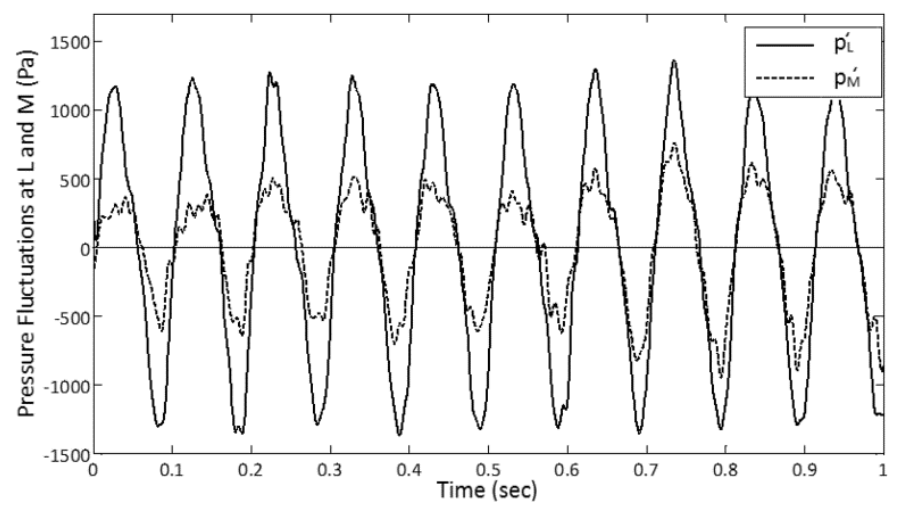

Figure 12: The time-varying values of pressure fluctuation at cross-sections located by point $L$ $\left(p_{L}^{\prime}(t) \equiv p_{L}(t)-\bar{p}_{L}\right)$ and $M\left(p_{M}^{\prime}(t) \equiv p_{L}^{\prime}(t)-\Delta p_{\text {OM1 }}(t)\right)$. These data are for run 4 of Tables 4-5.

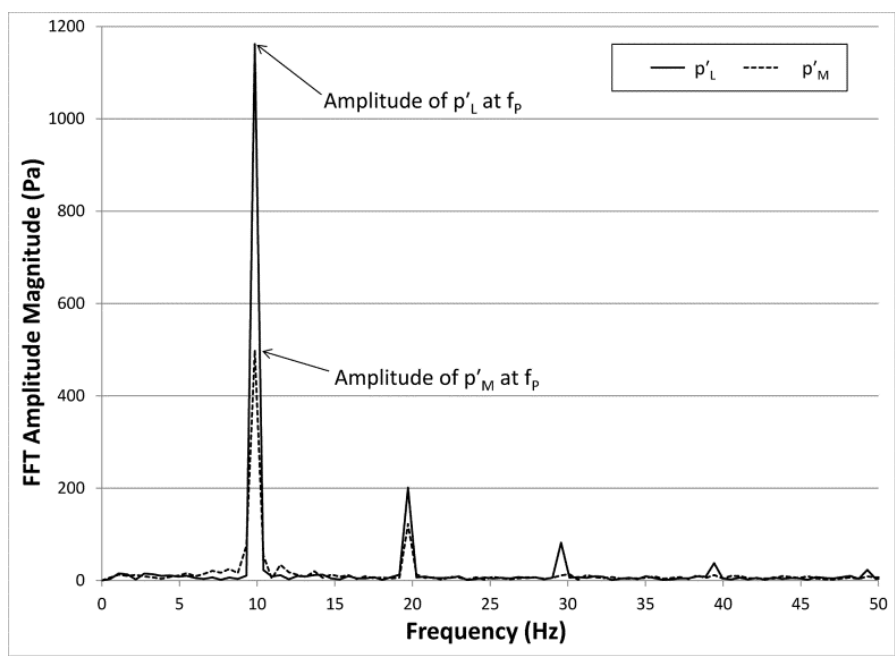

Figure 13: The FFT of $p_{L}^{\prime}(t)$ and $p_{M}^{\prime}(t)$ in Fig 12 . 


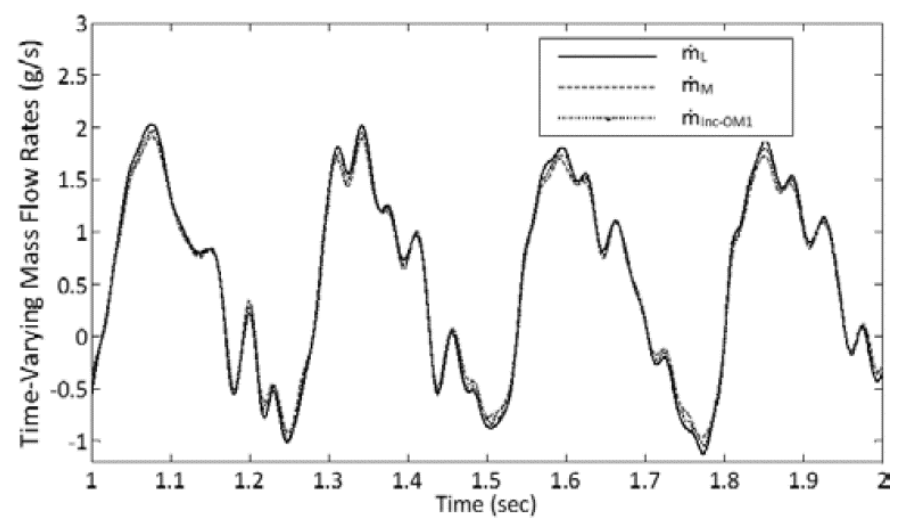

Figure 14: The incompressible mass flow rate values of $\dot{\mathrm{m}}_{\text {Inc|OM1 }}(\mathrm{t})$ for run 6 and its compressibility corrected values $\dot{m}_{L}(t)$ and $\dot{m}_{M}(t)$, respectively associated with points $L$ and $M$ in Fig. 2, are shown.

For now, it should be observed that though the above procedure for OM1 is also applicable to OM2, the absence of experimentally obtained values of pressure-difference between points $\mathrm{M}$ and $\mathrm{N}$ in Fig. 1 (or the absolute pressure measurements at point $\mathrm{N}$ ) makes it difficult to obtain compressibility corrected values of mass flow rate $\dot{\mathrm{m}}_{N}(\mathrm{t})$ from the known values of $\dot{\mathrm{m}}_{\mathrm{Inc|OM} 2}(\mathrm{t})$. The significant differences observed between the $\Delta \mathrm{p}_{\mathrm{OM} 1}(\mathrm{t})$ and $\Delta \mathrm{p}_{\mathrm{OM} 2}(\mathrm{t})$ curves in Fig. 6 and in the associated $\dot{\mathrm{m}}_{\mathrm{Inc} \mid \mathrm{OM} 1}(\mathrm{t})$ and $\dot{\mathrm{m}}_{\mathrm{Inc| \textrm {OM } 2}}(\mathrm{t})$ curves in Fig. 11 are discussed in Section 3.4.

For the properly instrumented orifice-meter OM1, the question remains as to how good is the proposed modeling approach for obtaining the cross-section dependent predictions for the mass flow rates $\dot{\mathrm{m}}_{\mathrm{L}}(\mathrm{t})$ and $\dot{\mathrm{m}}_{M}(\mathrm{t})$. This can be assessed by at least two different indirect approaches described in Sections 3.4.2 and 3.4.3. A direct verification method is outlined in Appendix A-2.

\subsubsection{Compressible Flow Simulations as an Indirect Modeling Verification Approach}

This result is taken from [1] and is presented here to show significance of my incompressible results. Instead of obtaining corrections on the CFD solution of the 
incompressible model problem in Eq. (4), one can also directly obtain the acoustic effects on the cross-sectional mass flow rate $\dot{m}(x, t)$ at any location $0 \leq x \leq I_{o m}$ in Fig. 8 (or Fig. 2). For this, one could computationally solve the compressible CFD model problems described below for the specific orifice meter in Fig. 2. The new estimates of $\dot{\mathrm{m}}_{\mathrm{L}-\mathrm{Comp}}(\mathrm{t}) \equiv \dot{\mathrm{m}}(\mathrm{x}=0, \mathrm{t})$ and $\dot{\mathrm{m}}_{\mathrm{M}-\mathrm{Comp}}(\mathrm{t}) \equiv \dot{\mathrm{m}}\left(\mathrm{x}=\mathrm{l}_{\mathrm{OM} 1}, \mathrm{t}\right)$ can be compared with $\dot{\mathrm{m}}_{\mathrm{L}}(\mathrm{t})$ and $\dot{\mathrm{m}}_{\mathrm{M}}(\mathrm{t})$ values obtained by the earlier approach in Section 3.4.1. This verification approach briefly described here and its full results are available in [1].

Fig. 15 shows a comparison between $\dot{\mathrm{m}}_{\text {stored }}(\mathrm{t})$ values obtained from this compressible flow CFD model and the ones obtained from the earlier compressibility correction theory on the incompressible CFD model (which has $\dot{\mathrm{m}}_{\text {stored }}(\mathrm{t})=0$ ). The excellent agreement between the two independent methods verifies the proposed compressibility correction theory for the incompressible CFD model. However, the order of magnitude of the $\dot{\mathrm{m}}_{\text {stored }}(\mathrm{t})$ term for the orifice-meter volumes are found to be typically small compared to the order of magnitude of the corresponding $\dot{\mathrm{m}}_{\text {Inc|om }}(\mathrm{t})$ term. This is why, in Fig. 16, principal fluctuations in the mass flow rate $\dot{m}_{M-C o m p}(t)$ obtained by the above compressible flow simulations closely agrees with both $\dot{\mathrm{m}}_{\mathrm{Inc|om}}(\mathrm{t})$ values and the values of $\dot{\mathrm{m}}_{\mathrm{M}}(\mathrm{t})$ obtained from the compressibility correction approach of Section 3.4.1. Such agreements are obtained for other cases as well [1]. These results point to a remarkable success and the value of the easier to implement method (for symmetric geometry) of Section 3.4.1. 


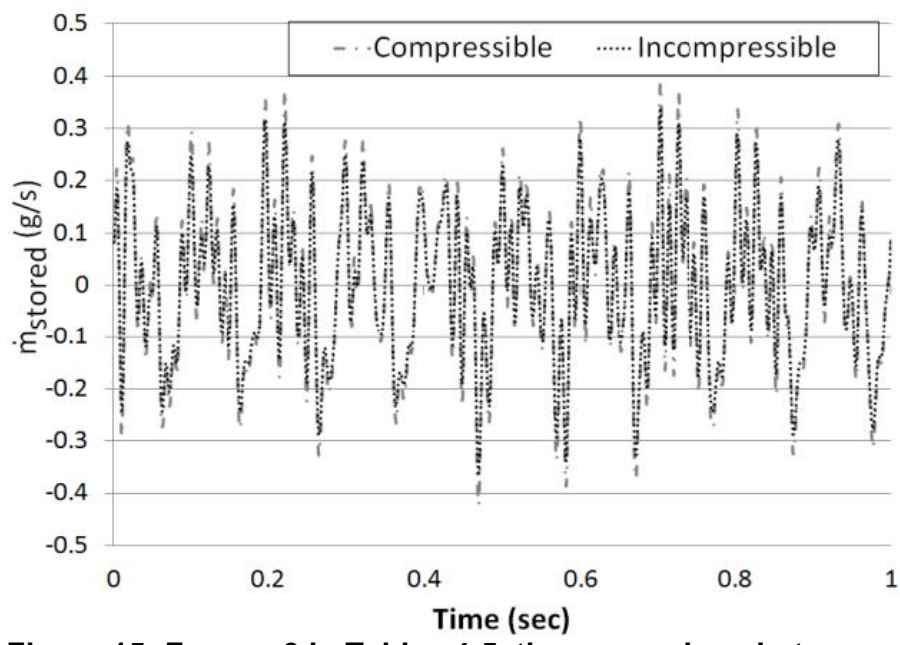

Figure 15: For run 3 in Tables 4-5, the comparison between $\dot{\mathbf{m}}_{\text {stored }}(t)$ values obtained from the compressible flow CFD model and their values obtained from the proposed compressibility correction theory (Eq. (17)) for the incompressible CFD model (which has $\dot{\mathrm{m}}_{\text {stored }}(\mathrm{t})=0$ ).

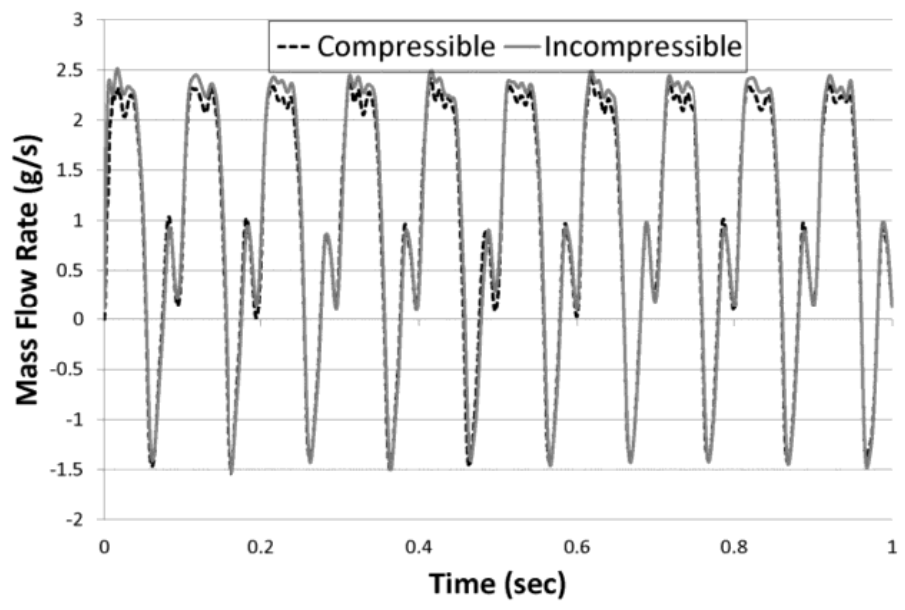

Figure 16: This plot shows, for run 3 in Tables 4-5, the comparison between mass flow rate $\dot{m}_{M-C o m p}(t)$ obtained from the compressible flow CFD model and $\dot{m}_{M}(t)$ obtained from a compressibility correction on the $\dot{m}_{\text {Inc|OM1 }}(t)$ values which are obtained from an incompressible CFD model.

\subsubsection{Alternative Indirect Modeling Verification Approach}

From the approach of Section 3.4.1 for obtaining time-varying mass flow rate at a specific cross-section, say $\dot{\mathrm{m}}_{\mathrm{M}}(\mathrm{t})$ at cross-section $\mathrm{M}$ in Fig. 1, one can use the proposed modeling principles to obtain an independent estimate for the time-varying mass flow 
rate at any other cross-section location (say point $\mathrm{N}$ in Fig. 3 - the inlet of orifice meter OM2 in Fig. 1). If one uses suitable variations of Eqs. (6), (12), and (16), one obtains:

$$
\dot{\mathrm{m}}_{\mathrm{N}}(\mathrm{t})=\dot{\mathrm{m}}_{\mathrm{M}}(\mathrm{t})-\frac{1}{\mathrm{c}_{0}^{2}} \int_{\mathrm{CV}_{\mathrm{f} \mid \mathrm{MN}}} \frac{\partial \mathrm{p}_{\text {off }}^{\prime}(\mathrm{x}, \mathrm{t})}{\partial \mathrm{t}} \cdot \mathrm{dvol}=\dot{\mathrm{m}}_{\mathrm{M}}(\mathrm{t})-\frac{1}{\mathrm{c}_{0}^{2}} \cdot \frac{\mathrm{d}}{\mathrm{dt}}\left[\mathrm{p}_{\mathrm{M}}^{\prime}(\mathrm{t})-\mathrm{NI}_{\mathrm{MN}}(\mathrm{t}) \cdot \Delta \mathrm{p}_{\mathrm{MN}}(\mathrm{t})\right] \cdot \mathrm{V}_{\mathrm{MN}},
$$

where $V_{0}, \Delta p_{o m}(t)$, and $\mathrm{I}(\mathrm{t})$ have been respectively replaced by the volume $\mathrm{V}_{\mathrm{MN}}$, pressure-difference $\Delta \mathrm{p}_{M N}(\mathrm{t})$, and integral $\mathrm{I}_{\mathrm{MN}}(\mathrm{t})$ that relate to their values for the region between points $\mathrm{M}$ and $\mathrm{N}$ in Fig. 1.

In principle, Eq. (25) above yields $\dot{\mathrm{m}}_{\mathrm{N}}(\mathrm{t})$ as a second independent estimate of $\dot{\mathrm{m}}_{\mathrm{N}}(\mathrm{t})$ obtained from $\dot{\mathrm{m}}_{\mathrm{M}}(\mathrm{t})$ - which is obtained by consideration of OM1 and the method of Section 3.4.1. Because of the absence of experimentally obtained values of pressuredifference between points $\mathrm{M}$ and $\mathrm{N}$ in Fig. 6 and the absolute pressure measurements at point $\mathrm{N}$ in Fig. 6, the above verification is not implemented here. Instead a new suggested verification approach is discussed in the following section.

\subsubsection{An Indirect Modeling Verification Approach for the New Inlet Geometry}

The new indirect verification approach makes use of a new inlet geometry. The geometry of the orifice meter has been kept the same as OM1 in the previous reported results [2], with the only change being in the reduction of tube lengths between the pressure tap locations and the instruments diaphragms. This change should allow for a more accurate pressure difference reading and the reduction of acoustic effects in these lines. In addition, now directly downstream of the orifice meter is the nozzle section. This section consists of a small straight section, followed by a reduction section, then another straight section. Both of these geometries are shown together in Figures 17. 


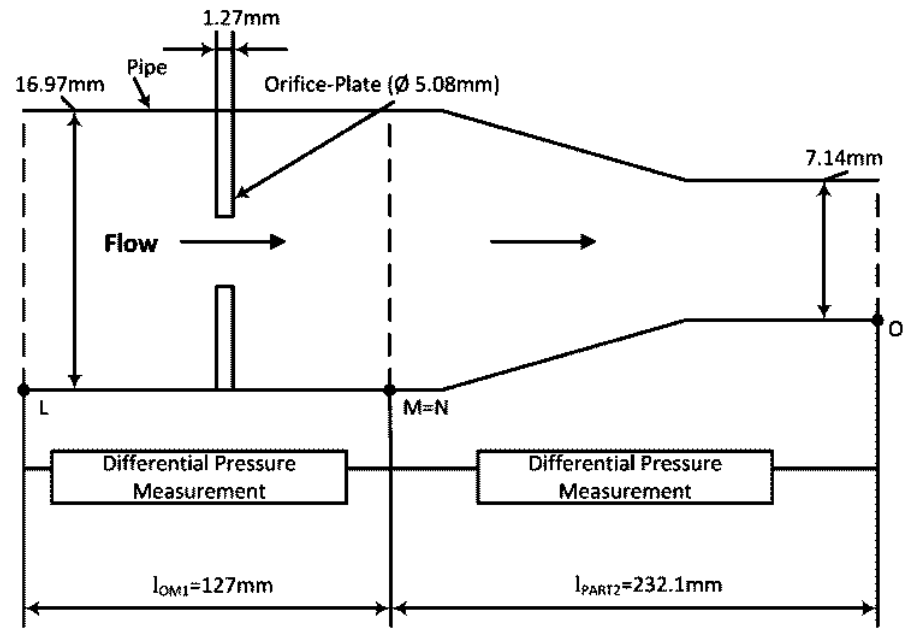

Figure 17: The geometry for the two devices that are merged together, with proper instruments, and placed between points $L$ and $O$ of Fig. 1.

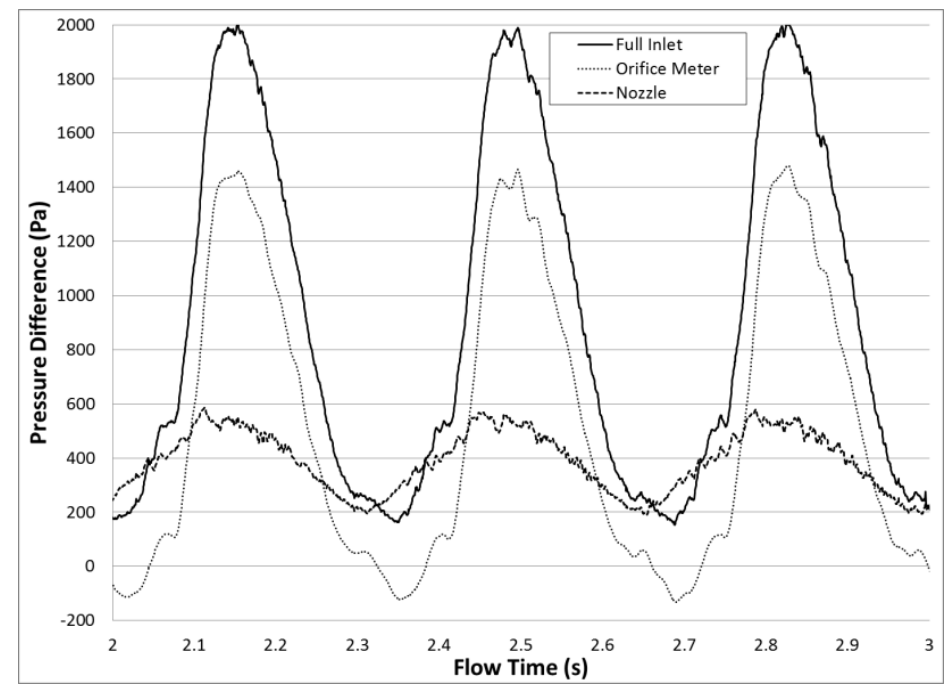

Figure 18: Pressure difference plot for new inlet geometry and a primary driving frequency of $3 \mathrm{~Hz}$.

During the experimental runs, the differential pressures, $\Delta_{\mathrm{LM}}(\mathrm{t})$ and $\Delta_{\mathrm{MN}}(\mathrm{t})$ in Fig. 18 are to be measured. But before the first experiments were conducted, the new geometry was simulated in Fluent and for a representative pulsatile inlet mass flow rate it was found that the pressures remained approximately uniform at the cross-sections 
where the pressure taps were located. This was again verified with experimental gathered pressure difference data.

Both of the pressure transducers shared a common port at the point $L$ in Fig. 17. Thus, for the range of mass flow rates and frequencies/amplitudes considered here, it is said that $P_{L}(t), P_{M}(t)=P_{N}(t)$, and $P_{O}(t)$ are approximately uniform across the cross-section. The below outlines the proposed approach for the indirect verification on the new inlet geometry:

(I) First apply the incompressible approach and compressibility correction as described earlier in Section 3.4.1 to get:

$$
\begin{aligned}
& \dot{m}_{L}(t) \cong \dot{m}_{I N C \mid O M}(t)+\Delta \dot{m}_{L}(t) \\
& \dot{m}_{M}(t) \cong \dot{m}_{I N C \mid \text { Nozzle }}(t)+\Delta \dot{m}_{N}(t)
\end{aligned}
$$

(II) Use full geometry and the methodology of Section 3.4 between points $L$ and O in Fig. 17 to obtain:

$$
\dot{m}_{O}(t)=-\dot{m}_{\text {Stored }-L O}(t)+\dot{m}_{L}(t)
$$

(III) Use Nozzle geometry between points $\mathrm{N}$ and $\mathrm{O}$ in Fig. 17 to obtain:

$$
\dot{m}_{N}(t) \equiv \dot{m}_{O}(t)+\dot{m}_{\text {Stored }-N O}(t)
$$

Because the points $\mathrm{M}$ and $\mathrm{N}$ are common between the exit geometry of the orifice meter and the inlet of the nozzle, the two points are effectively merged together as shown in Fig. 17. Their predicted mass flow rates should then closely align.

Further results and discussions of the initial inlet geometry tests are reported in Appendix A-1. 


\section{Results and Discussion}

In the previous sections, the detailed methodology for obtaining the time-varying mass flow rate at a specific cross-section in the gas flow of Fig. 1 was defined.

This thesis shows under incompressible modeling, one gets reasonably accurate (with proper grid and time independence) time vary mass flow rates. Despite this when, for the same run (as in Fig. 11), incompressible simulations mass flow rates for OM1 and $\mathrm{OM} 2$ are done, the results show a clear difference. This means that the compressibility effects are important between OM1 and OM2.

Upon review of the contribution from Nikhil Ajotikar [16], errors were found in the implementation of the CFD modeling. The work carried out by myself here assessed and corrected these errors, along with refining the proposed algorithm of finding the time varying mass flow rate. In addition, a model and indirect verification approach was also completed for initial runs of a new inlet geometry. This approach requires the solution from the incompressible and unsteady gas flow problems modeled by Eq. (4). The experimental approach described for the flow-loop in Fig. 1 provided the dynamic differential and absolute pressure data, $\Delta \mathrm{p}_{\mathrm{OM}}(\mathrm{t})$ and $\Delta \mathrm{p}_{\text {Nozzle }}(\mathrm{t})$, which are concurrently obtained for the orifice meter and nozzle (see Fig. 17) and used in the solution of Eq. (4). This data was then used to obtain the incompressible mass flow rates whose representative behaviors are shown in Appendix A-1. Forthcoming results (discussed in Appendix A-1) from this experiment are expected to show closer agreement between the mass flow rates across the orifice meter and nozzle. 


\section{Conclusions and Future Work}

\subsection{Uses in Future Experimental Research Work and Industry}

The results and methodology developed here and in [2] will be used in up and coming research where the accurate measurement of the mass flow rate at the inlet of the test section is extremely important. In addition, this procedure may also be used within the nature gas and other process industries where accurate mass flow rate measurements are important for process controls and possible enhancements in heat exchanger surfaces. By measuring and controlling the time-varying mass flow rate on condenser surfaces it is possible to achieve great enhancement as shown in [8]. This device can be used for the automotive industry with gas flows in and out of an internal combustion engine, where accurate modeling of the reactions occurring (either within the engine itself or in the exhaust downstream, i.e. catalytic converter) is needed.

\subsection{Future Corrections and Verification}

Future work includes pinpointing the source of discrepancies show in the results of Appendix A-1. Possible causes such as liquid or other blockages in the lines should first be examined. If this is not the case for the mass flow rate discrepancies, other possibilities (such as: instrumentation errors or acoustic effects from the inlet of the test section) should next be investigated. The correction of these errors is expected to bring the predicted mean mass flow rates in line with the values measured at the Coriolis meter. In addition, if higher accuracy on the predicted mass flow rate from this orifice device is desired, a direct experimental verification approach is also available for reference in the Appendix. It is possible to conduct this verification simultaneously as the above experiment conducted here. A final further investigation should include a full thermal modeling of the inlet assembly. During the runs recorded here (and in previous 
results) it was noted that vapor temperatures downstream of the orifice plate were significantly higher $\left(6-8^{\circ} \mathrm{C}\right)$ above those at the inlet of the orifice meter. While some temperature rise is to be expected due to the electrical heating of the pipes and orifice meter structure, this temperature rise was much higher than seen elsewhere in the flow loop. 


\section{References}

[1] M. Zhao, 2013, "Compressible Computational Simulations for a Time-Varying Pulsatile Gas Flow Measurement Technique”, Masters Report, Michigan Technological University.

[2] A. Narain, N. A., M. T. Kivisalu, A. F. Rice, M. Zhao, N. Shankar, 2012, "Obtaining Time-Varying Pulsatile Gas Flow Rates with the Help of Dynamic Pressure-Difference and Other Measurements for an Orifice-Plate Meter," Journal of Fluids Engineering.

[3] Mckee, R., 1989, "Pulsation Effects on Orifice Metering Considering Primary and Secondary Elements," eds., pp. 112-118.

[4] Gajan, P., Mottram, R. C., Hebrard, P., Andriamihafy, H., and Platet, B., 1992, "The Influence of Pulsating Flows on Orifice Plate Flowmeters," Flow Measurement and Instrumentation, 3(3), pp. 118-129.

[5] Mosley, D. S., 1966, "Measurement Error in the Orifice Meter on Pulsating Water Flow," eds., Pittsburgh, USA, pp. 103-123.

[6] Mottram, R. C., 1981, "Measuring Pulsating Flows with a Differential Pressure Meter " Proc. Proceedings 2nd Internation Symposium On Fluid Flow Measurements, Instruments Society of America, pp. 347-361.

[7] Mottram, R. C., 1974, "The Measurement of Pulsating Flows using Orifice Plate Meters," Flow: Its Measurements and Control in Science and Industry R. B. Dowell, ed., ASME Instruments Society of America, pp. 197-208.

[8] Kivisalu, M. T., Gorgitrattanagul, P., Narain, A., Naik, R., and Hasan, M., 2013, "Sensitivity of Shear-Driven Internal Condensing Flows to Pressure Fluctuations and Its Utilization for Heat Flux Enhancements," International Journal of Heat and Mass Transfer, 56(1-2), pp. 758-774.

[9] Kivisalu, M., 2013, "Experimental Investigation of Internal Condensing Flows, Their Sensitivity to Pressure Fluctuations and Heat Transfer Enhancements," Ph.D. thesis, Michigan Technological University.

[10] Cheesewright, R., and Clark, C., 1998, "The Effect of Flow Pulsations on Coriolis Mass Flow Meters," Journal of Fluids and Structures, 12(8), pp. 1025-1039.

[11] Vetter, G., and Notzon, S., 1994, "Effect of Pulsating Flow on Coriolis Mass Flowmeters," Flow Measurement and Instrumentation, 5(4), pp. 263-273.

[12] 2010, User Guide and Theory Guide ANSYS FLUENT 13.0.

[13] Davidson, L., 2003, "An Introduction to Turbulence Models," Department of Thermo and Fluid Dynamics Chalmers University of Technology, Sweden.

[14] Kundu, P. K., and Cohen, I. M., 2007, Fluid Mechanics, Academic Press, Amsterdam ; Boston.

[15] Wilcox, D. C., 2006, Turbulence Modeling for CFD, DCW Industries, Inc.

[16] N. Ajotikar, 2011, "A Synthesis of Computations and Experiments for Obtaining Pulsatile Gas Flow Rates from Dynamic Pressure Difference Measurements Across an Orifice-plate Meter ", Masters Report, Michigan Technological University.

[17] T. W. Ng, A. Narain, M. Kivisalu, 2010, "'Fluorescence and Fiber-Optics Based Real-Time Thickness Sensor for Dynamic Liquid Films," ASME Journal of Heat Transfer, 132(031603), pp. 1 to 12. 


\section{Appendix}

\section{A-1: Initial results from New Indirect Verification Approach as Proposed in Section}

3.4.4

\section{A-1.1 Mesh Construction and Grid Independence Testing for the New Inlet Geometry}

A similar methodology as described in Section 3.1 for the orifice meter geometry was also conducted for the two new geometries (nozzle and full inlet). Each mesh was tested for a range of steady state conditions and their results displayed along with the original OM1 in Table A-1 (The MQQ values shown in the table are Fluent's indication of the mesh quality, over a scale of 0 to 1 , with 1 being the highest quality). It was found that a mesh of the same size as that used for the original OM1 was also suitable for modeling the nozzle and thus the full inlet section. The same held for the time-step size $(\Delta t=0.0005$ seconds) and turbulence model ( $k-\varepsilon$ turbulence model). Thus, for all results reported here a mesh size of $0.0004 \mathrm{~m}$ (Mesh 4) and a time step of 0.0005 seconds are said to be used.

Table A-1: Grid independence results for the new inlet geometry

\begin{tabular}{|c|c|c|c|c|c|c|c|}
\hline \multicolumn{3}{|c|}{ Full Inlet } & \multicolumn{5}{|c|}{ Steady State Mass Flow Rate $(\mathrm{kg} / \mathrm{s})$ for the following Inlet Total Pressure } \\
\hline Mesh Name & Mesh Size & Elements & P_in=1000Pa & P_in=600Pa & $P_{\text {_in }}=200 \mathrm{~Pa}$ & P_in=25Pa & MQQ \\
\hline Mesh 2 & $1 e-4 m$ & \begin{tabular}{|r|}
79508 \\
\end{tabular} & \begin{tabular}{|l|}
0.002926 \\
\end{tabular} & 0.002231 & 0.001201 & \begin{tabular}{|r|}
0.000362 \\
\end{tabular} & 0.799000 \\
\hline Mesh 3 & $2 e-4 m$ & 63022 & 0.002454 & 0.001867 & 0.001027 & 0.000315 & 0.716000 \\
\hline Mesh 4 & $4 e-4 m$ & 15746 & 0.002351 & 0.001790 & 0.000984 & 0.000282 & 0.751220 \\
\hline Mesh 5 & $8 e-4 m$ & 4540 & 0.002360 & 0.001799 & 0.000988 & 0.000292 & 0.710340 \\
\hline \multicolumn{8}{|c|}{ Orifice Meter OM1 } \\
\hline Mesh Name & Mesh Size & Elements & & & & & \\
\hline Mesh 1 & $8 e-5 m$ & 168534 & 0.002812 & 0.002221 & 0.001416 & 0.000921 & 0.876700 \\
\hline Mesh 2 & $1 e-4 m$ & 107344 & 0.004191 & 0.003315 & 0.001962 & 0.000749 & 0.802880 \\
\hline Mesh 3 & $2 e-4 m$ & 27104 & 0.011369 & 0.008004 & 0.004195 & 0.000885 & 0.886200 \\
\hline Mesh 4 & $4 e-4 m$ & 9250 & 0.002718 & 0.002106 & 0.001217 & 0.000424 & 0.841200 \\
\hline Mesh 5 & $8 e-4 m$ & 2829 & 0.002696 & 0.002090 & 0.001204 & 0.000419 & 0.789400 \\
\hline Mesh 6 & $8 e-3 m$ & 864 & 0.002715 & 0.002103 & 0.001213 & 0.000422 & 0.816200 \\
\hline Mesh 7 & $5 e-3 m$ & 569 & 0.002740 & 0.002121 & 0.001216 & 0.000418 & 0.755600 \\
\hline Mesh 8 & $1 e-2 m$ & 325 & 0.002713 & 0.002105 & 0.001210 & 0.000416 & 0.816560 \\
\hline Mesh 9 & $8 e-2 m$ & 145 & 0.002448 & 0.001901 & 0.001102 & 0.000392 & 0.984800 \\
\hline \multicolumn{8}{|c|}{ Nozzle } \\
\hline Mesh Name & Mesh Size & Elements & & & & & \\
\hline Mesh 2 & $1 \mathrm{e}-4 \mathrm{~m}$ & 108804 & 0.012955 & 0.009844 & 0.005538 & 0.001709 & 0.709430 \\
\hline Mesh 3 & $2 e-4 m$ & 36106 & 0.011369 & 0.008004 & 0.004195 & 0.000885 & 0.777700 \\
\hline Mesh 4 & $4 e-4 m$ & 9044 & 0.005887 & 0.004314 & 0.002144 & 0.000521 & 0.828600 \\
\hline Mesh 5 & $8 e-4 m$ & 2760 & 0.006131 & 0.004458 & 0.002202 & 0.000511 & 0.483600 \\
\hline Mesh 7 & $5 e-3 m$ & 1889 & 0.006166 & 0.004482 & 0.002206 & 0.000511 & 0.479900 \\
\hline
\end{tabular}




\section{A-1.2 Preliminary Results for the Time Vary Mass Flow Rate of the New Inlet}

Initial runs of the new inlet geometry provided a chance to experience the steep learning curve associated with new instrumentation. During the first runs pressure data was collected in the same manner as described in Section 2. But, after the first set of runs with the new inlet, it was found that the connection lines between the orifice meter and the differential pressure transducers were not properly insulated nor heated, resulting in vapor condensing and pooling in the transducer connection lines. This was immediately corrected with a second run in which the lines were further insulated and heated to well above the saturation temperature $\left(5-10^{\circ} \mathrm{C}\right)$.

Following the procedure outlined in Section 3.3 and 3.5, the mass flow rate was found for the three computed geometries (full inlet, orifice meter, and nozzle). The results are shown in Fig. A-1. It is immediately obvious that there is poor agreement between these results. Even with the empirical correction of Section 3.2, the results still do not show agreement as seen in Figure A-2. The predicted mass flow rate from the

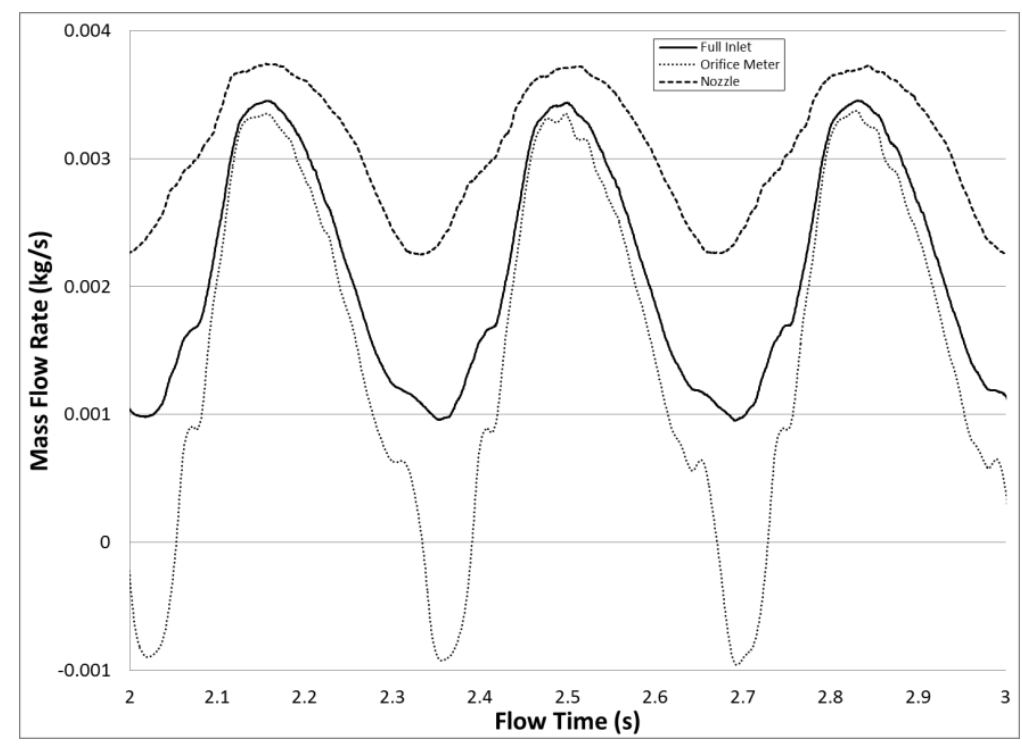

Figure A-1: Raw mass flow rate results for the new inlet geometry 
orifice meter does have good agreement with the measured mean mass flow rate and previous results (see Table 4-5), but the nozzle section exhibits significant variations from the measured mean mass flow rate.

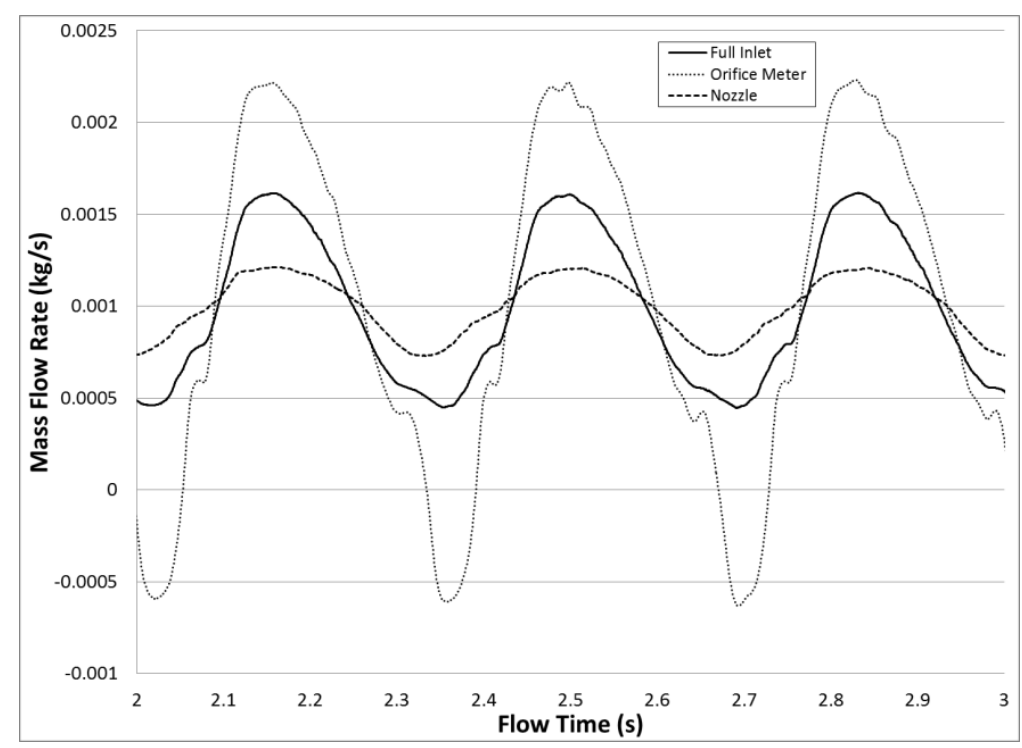

Figure A-2: Alpha corrected mass flow rates for the new inlet geometry

An FFT of the alpha corrected mass flow rate was also completed and shown in Fig. A-3. Here the difference in amplitude at the primary driving frequency $(3 \mathrm{~Hz})$ is apparent.

After this difference in mass flow rates was found, it was first necessary to validate these results and eliminate and possible computational errors. This was done by using the computed mass flow rate (shown in Fig. A-1) to find the expected pressure drop across the geometry from an incompressible model. First, the computed mass flow rate (Fig. A-1) was converted into an average velocity at the inlet by the simple form $\overline{V e l}=\dot{m} /\left(\rho^{*} A_{\circ}\right)$. This average velocity was then specified as an inlet boundary condition and the exit boundary condition remained as $P=0$. The computed area weighted average pressure along the inlet was recorded during the simulation. As shown in Fig. A4 , this pressure is well aligned with the original recorded pressure with the mean of each 


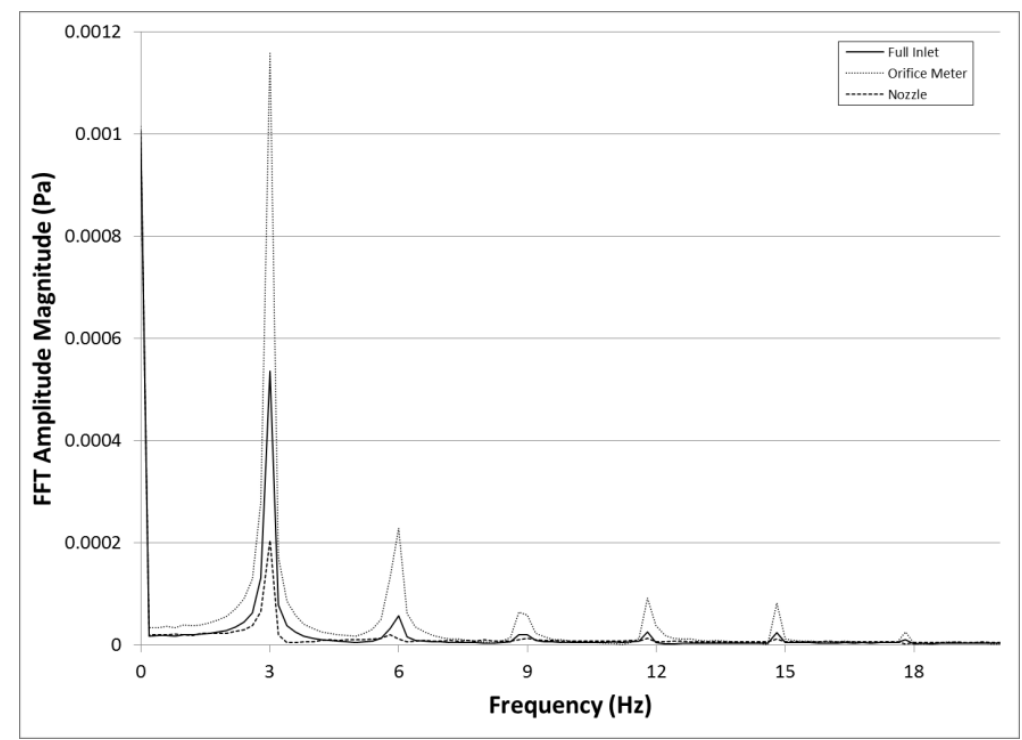

Figure A-3: FFT magnitude plot of the alpha corrected mass flow rate data shown in Fig. A-2

within $1.3 \%$. This result confirms suspensions that the original experimental differential pressure data for the nozzle (and possibly the orifice meter) are not correct. This is suspected to be caused by liquid in the differential pressure lines, blockages, or transducer calibration issues. Subsequent runs will address this issue and it is expected that the difference in the incompressible mass flow rate results will greatly reduce.

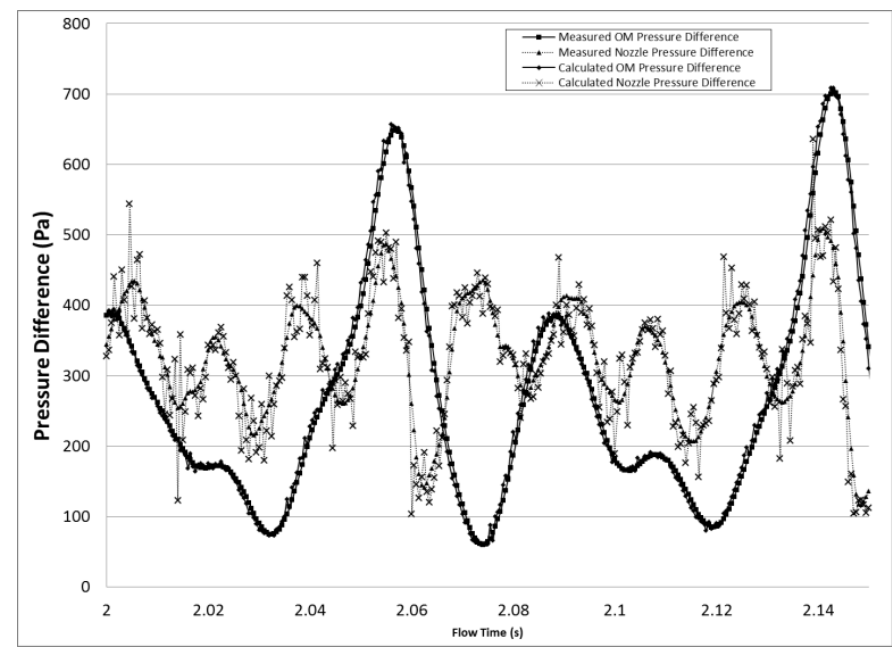

Figure A-4: Measured and computed pressure difference across the orifice meter and nozzle of the new geometry for a representative $10 \mathrm{~Hz}$ LA case 


\section{A-2: A Recommended Experimental Approach for Direct Validation of the Orifice Meter Design}

A direct experimental validation requires a direct experimental approach for measuring the time-varying mass flow rate $\dot{\boldsymbol{m}}_{\boldsymbol{M}}(\boldsymbol{t})$ at the cross-section location denoted by point $\mathrm{M}$. The proposed experiment is neither trivial nor inexpensive. However, by shifting the dynamic mass flow rate prediction point $M$ in Fig. 1 (shown downstream of the orificemeter OM1) to a new location (see Fig. A-5) far away from the downstream end of OM1 and continuing to measure $\Delta \boldsymbol{p}_{L M}(\boldsymbol{t})$, one can again predict the time-varying $\left.\dot{m}_{M}\right|_{\text {Actual }}(t)$ by the procedure in Section 3. If this new location $\mathrm{M}$ allows one to directly measure the

experimental values of time-varying mass flow rate and denote it as $\left.\dot{m}_{M}\right|_{\text {Actual-Direct }}(t)$, a direct validation and error assessments of the proposed inexpensive procedure of Section 3 is possible. However a direct experimental verification approach will only be necessary if one wants to market this device with definitive understanding of its accuracy limits.

The recommended experiment involves replacing the flow loop in Fig. 1 by the recommended flow loop set up in Fig. A-5. Once a quasi-steady pulsatile flow is achieved for the closed flow loop (the 3-way valve $\mathrm{V}^{*}$ directs the flow to the condenser) in Fig. 18 for a certain time duration $t^{*} \leq t \leq t^{* *}$, the 3 -way valve setting for $V^{*}$ in Fig. 18 is changed to direct the flow away from the vertical tube condenser to the direct contact pool condenser $\mathrm{C}_{\text {Direct }}$ (which is properly cooled and well stirred). Note that the downstream end point $\mathrm{M}$ of the differential pressure transducer now denotes the end of the tube (superheated and insulated) which is feeding the slightly superheated vapor to the direct contact pool condenser $C_{\text {Direct }}$. With the geometry between points $L$ and $M$ (of Fig. 18) taken into proper consideration, the method of Section 3 will yield $\left.\dot{m}_{M}\right|_{\text {Actual }}(t)$ for a time interval $t^{*} \leq t \leq t^{* *}$ for which steady-in-the-mean pulsatile behavior is observed 
in the dynamic pressure-difference data (between points $L$ and $M$ of Fig. A-5) obtained from the differential pressure-transducer.

The well stirred pool condenser $\mathrm{C}_{\text {Direct }}$ is designed to condense all of the incoming pulsatile vapor flow over $\mathrm{t}^{\star} \leq \mathrm{t} \leq \mathrm{t}^{\star *}$. For $\mathrm{t} \leq \mathrm{t}^{*}$, the pool condenser has a known mass of FC-72 $\left(\mathrm{M}_{0-\mathrm{FC} 72}\right)$ and is mixed with a known amount of a dopant bi-acetyl $\left(\mathrm{M}_{0 \text {-biacetyl }}\right)$. This dopant has very good light absorption characteristics for $\lambda$ in the $400-420 \mathrm{~nm}$ range (see [17]). The initial as well as subsequent concentration of bi-acetyl can be dynamically measured by a fast response (and well calibrated) dipping probe type spectro-photometer (available from Ocean Optics, Inc.). The spectrophotometer is shown as $S_{p}$ in Fig. A-5 and is connected to an oscilloscope (not shown in Fig. A-5). Since the time-scale associated with bi-acetyl's diffusion (well stirred $\mathrm{C}_{\text {Direct }}$ ) and vapor condensation time-scales in $\mathrm{C}_{\text {Direct }}$ can be made to be much faster than those associated with the pulsatile flows, the method is likely to yield real time concentration $\mathrm{C}(\mathrm{t})=\mathrm{M}_{0 \text {-biacety }} / \mathrm{M}_{\mathrm{FC} 72}(\mathrm{t})$ (where $\left.M_{F C 72}(t) \cong M_{0-F C 72}+\left.\int_{t^{*}}^{t} \dot{m}_{M}\right|_{\text {Actual-Direct }}(t) \cdot d t\right)$ for such flows. Note that the concentration $\mathrm{C}\left(\mathrm{t}^{*}\right)=\mathrm{M}_{0 \text {-biacetyl }} / \mathrm{M}_{0-\mathrm{FC} 72}$ is known both directly as well as through a reading from the spectrophotometer.

The above direct measurement of concentration $C(t)$ is easily converted, within experimental errors, to yield a time-history of $\left.\dot{m}_{M}\right|_{\text {Actual-Direct }}(t)$. For a suitable subinterval of $t^{*} \leq t \leq t^{* *}$, the percentage accuracy within which

$$
\left.\left.\dot{m}_{M}\right|_{\text {Actual }}(t) \cong \dot{m}_{M}\right|_{\text {Actual-Direct }}(t)
$$

is actually satisfied will provide for a direct validation and error estimation approach for the more practical and inexpensive procedure described in Section 3. 


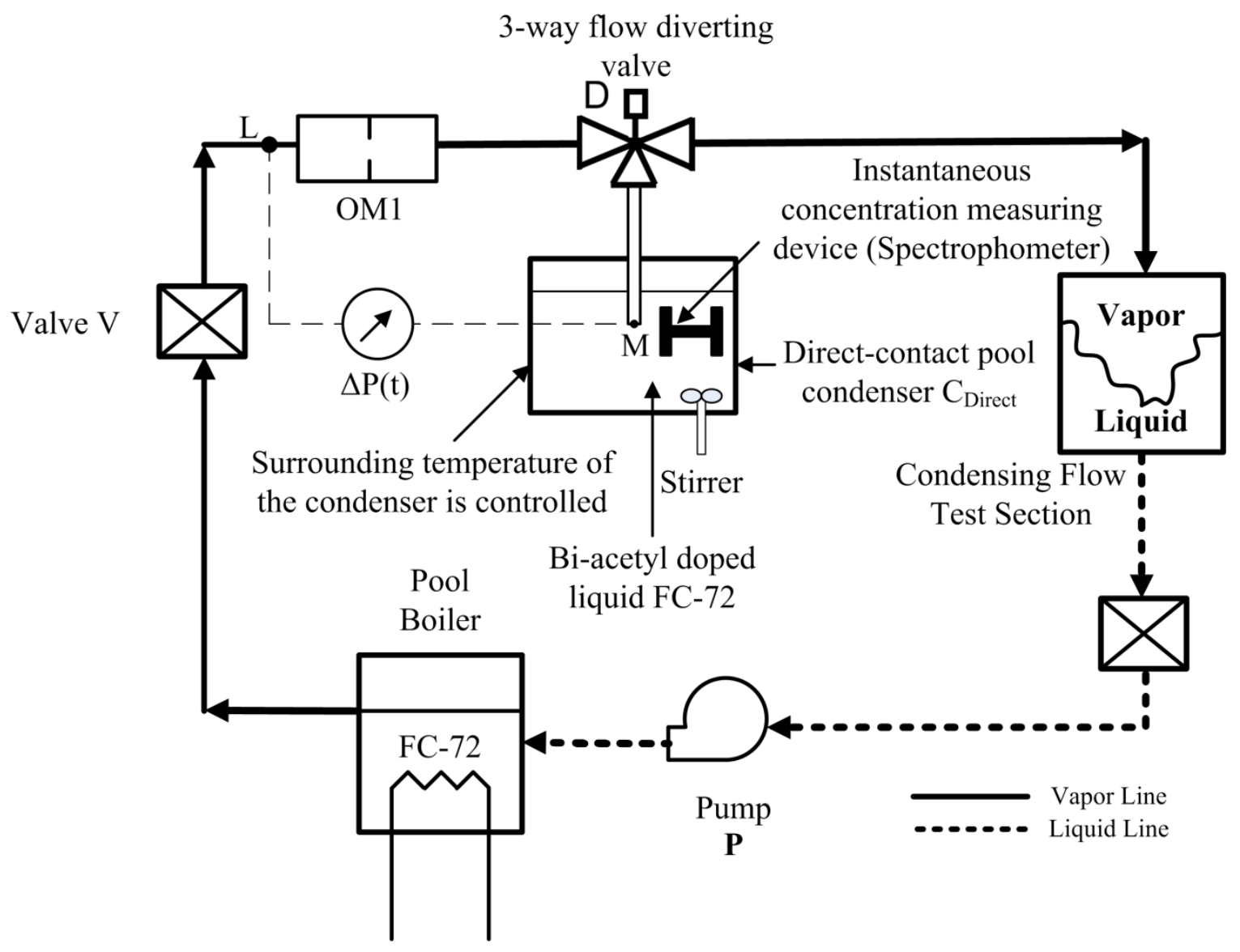

Fig. A-5: The proposed direct validation experimental flow-loop. 